\title{
Heteromeric Acid-Sensing Ion Channels (ASICs) Composed of ASIC2b and ASIC1a Display Novel Channel Properties and Contribute to Acidosis-Induced Neuronal Death
}

\author{
Thomas W. Sherwood, Kirsten G. Lee, Matthew G. Gormley, and Candice C. Askwith \\ Department of Neuroscience, The Ohio State University, Columbus, Ohio 43210
}

Acid-sensing ion channel (ASIC) subunits associate to form homomeric or heteromeric proton-gated ion channels in neurons throughout the nervous system. The ASIC1a subunit plays an important role in establishing the kinetics of proton-gated currents in the CNS, and activation of ASIC1a homomeric channels induces neuronal death after local acidosis that accompanies cerebral ischemia. The ASIC2b subunit is expressed in the brain in a pattern that overlaps ASIC1a, yet the contribution of ASIC2b has remained elusive. We find that coexpression of ASIC2b with ASIC1a in Xenopus oocytes results in novel proton-gated currents with properties distinct from ASIC1a homomeric channels. In particular, ASIC2b/1a heteromeric channels are inhibited by the nonselective potassium channel blockers tetraethylammonium and barium. In addition, steady-state desensitization is induced at more basic $\mathrm{pH}$ values, and Big Dynorphin sensitivity is enhanced in these unique heteromeric channels. Cultured hippocampal neurons show proton-gated currents consistent with ASIC2b contribution, and these currents are lacking in neurons from mice with an ACCN1 (ASIC2) gene disruption. Finally, we find that these ASIC2b/1a heteromeric channels contribute to acidosis-induced neuronal death. Together, our results show that ASIC2b confers unique properties to heteromeric channels in central neurons. Furthermore, these data indicate that ASIC2, like ASIC1, plays a role in acidosis-induced neuronal death and implicate the ASIC2b/1a subtype as a novel pharmacological target to prevent neuronal injury after stroke.

\section{Introduction}

The acid-sensing ion channels (ASICs) are voltage-insensitive cation channels activated by extracellular acidification (Waldmann et al., 1997; Waldmann, 2001). There are four ASIC genes (ACCN1-4) that encode at least six individual ASIC subunits with distinct and overlapping patterns of expression (Wemmie et al., 2006; Xiong et al., 2008). Individual ASIC subunits associate into homomeric channels composed of three identical ASIC subunits and heteromeric channels composed of different ASIC subunits (Bassilana et al., 1997; Jasti et al., 2007). The ASIC1a subunit is expressed in neurons throughout the brain and is required for high-affinity proton sensing in central neurons (Wemmie et al., 2002). ASIC1a is also required for normal fear-related behaviors, learning, memory, and seizure termination (Wemmie et al., 2002, 2003; Coryell et al., 2008; Ziemann et al., 2008, 2009). In addition, ASIC1a plays a causative role in neuronal damage induced by prolonged acidosis (Xiong et al., 2004; Gao et al., 2005; Sher-

Received April 2, 2011; revised May 5, 2011; accepted May 15, 2011.

Author contributions: T.W.S. and C.C.A. designed research; T.W.S., K.G.L., and M.G.G. performed research; T.W.S. and C.C.A. analyzed data; T.W.S. and C.C.A. wrote the paper.

This work was supported by an NIH R01 grant to C.C.A. and an NIH P30 grant to C. Beattie, as well as an American Heart Association Predoctoral Student Fellowship to T.W.S. We thank K. Mykytyn and E. (Hoagland) Frey for helpful discussions and comments on this manuscript. We are grateful to M. Welsh, J. Wemmie, and M. Price for supplying CDNA clones and transgenic animals.

Correspondence should be addressed to C. C. Askwith, 4197 Graves Hall, 333 West 10th Avenue, Department of Neuroscience, The Ohio State University, Columbus, OH 43210. E-mail: Askwith.1@osu.edu.

DOI:10.1523/JNEUROSCI.1665-11.2011

Copyright $\odot 2011$ the authors $\quad 0270-6474 / 11 / 319723-12 \$ 15.00 / 0$ wood and Askwith, 2009). Inhibiting ASIC1a activity is neuroprotective in mouse models of stroke, and ASIC1a has also been implicated in the neuronal pathogenesis of multiple sclerosis, Huntington's disease, and Parkinson's disease (Xiong et al., 2004; Friese et al., 2007; Pignataro et al., 2007; Arias et al., 2008; Wong et al., 2008). Together, these results indicate that ASIC1a plays important roles in neuronal signaling and death in the brain. Yet, the contribution of other ASIC subunits to these processes has not been fully elucidated.

Two ASIC2 subunits are abundantly expressed in central neurons in a pattern that overlaps with ASIC1a (Price et al., 1996; Lingueglia et al., 1997). ASIC2a and ASIC2b are transcript variants distinct in the first one-third of the coding region (Lingueglia et al., 1997). ASIC2a forms homomeric channels, but their role in vivo is uncertain as severe acidification is required for their activation. ASIC2a also forms heteromeric channels with ASIC1a (ASIC2a/1a) that display unique characteristics compared with ASIC1a and ASIC2a homomers, including differences in apparent proton sensitivity and inactivation kinetics (Bassilana et al., 1997; Baron et al., 2002a; Askwith et al., 2004; Chu et al., 2004). ASIC2a/1a channels are abundant in central neurons and are responsible for a subset of proton-gated currents (Baron et al., 2002a; Askwith et al., 2004; Gao et al., 2004; Wu et al., 2004; Chu et al., 2006; Jiang et al., 2009). The other ASIC2 subunit, ASIC2b, does not produce proton-gated current when expressed alone, and it is unknown whether ASIC2b/1a channels have unique properties (Coscoy et al., 1999; Hesselager et al., 2004). Thus, the role of ASIC2b in central neurons is unknown. 
Here we show that coexpression of ASIC2b with ASIC1a results in ASICs that display novel properties that are distinct from ASICla homomeric and ASIC2a/1a heteromeric channels. We find proton-gated currents in cultured neurons with properties similar to ASIC2b/1a channels, and these currents contribute to acid-induced cell death. Together, these results directly implicate ASIC2 in neuronal injury and suggest that the unique ASIC2b/1a channel subtype plays a role in ASICla-dependent processes.

\section{Materials and Methods}

Recombinant DNA expression in Xenopus oocytes. Unfertilized oocytes were harvested from female Xenopus laevis purchased from Xenopus I, using standard procedures (Sherwood and Askwith, 2009). One to three hours after isolation, oocyte nuclei were injected with the pMT3 expression plasmid containing mouse ASIC cDNA (at $\sim 5 \mathrm{ng}$ of a $100 \mathrm{ng} / \mu \mathrm{l}$ stock) using a PV820 Pneumatic Picopump (World Precision Instruments). Oocytes were incubated at $18^{\circ} \mathrm{C}$ for $18-72 \mathrm{~h}$ before experiments were performed.

Two-electrode voltage clamp on Xenopus oocytes. Whole-cell macroscopic current was measured using the two-electrode voltage-clamp technique at a holding potential of $-60 \mathrm{mV}$ unless otherwise noted (Sherwood and Askwith, 2009). Electrodes $(\sim 2 \mathrm{M} \Omega$ ) were pulled using a Sutter P-97 micropipette puller (Sutter Instrument Company) and filled with $3 \mathrm{M} \mathrm{KCl}$. Data were acquired using an Oocyte Clamp OC-725 Amplifier (Warner Instruments), an Axon Digidata 1200 digitizer, and pCLAMP-8 software (Molecular Devices). Most experiments were done using Frog Ringer's solution (116 mм NaCl, 2 mм KCl, 5 mм HEPES, 5 mM MES, $2 \mathrm{mM} \mathrm{CaCl}_{2}, 1 \mathrm{~mm} \mathrm{MgCl}_{2}$ ) with a $\mathrm{pH}$ adjusted to the indicated levels using $1 \mathrm{~N} \mathrm{NaOH}$ or $1 \mathrm{~N} \mathrm{HCl}$. Because ASIC2b/1a heteromeric channels display steady-state desensitization at $\mathrm{pH} 7.4$, basal $\mathrm{pH}$ for all experiments was $\mathrm{pH} 7.9$ (unless stated otherwise). Barium, tetraethylammonium (TEA), zinc, $N, N, N^{\prime}, N^{\prime}$-tetrakis(2-pyridylmethyl)ethylenediamine, and psalmotoxin 1 (PcTX1) experiments were done with Ringer's solution that also contained $\mathrm{BaCl}_{2}$, tetraethylammonium chloride, $\mathrm{ZnCl}_{2}$, TPEN, or purified PcTX1 peptide (Peptides International) at the concentrations indicated in the figures and figure legends. Ion permeability studies were done with modified Frog Ringer's solution containing $0.4 \mathrm{~mm} \mathrm{CaCl}_{2}, 1 \mathrm{~mm} \mathrm{MgCl}_{2}, 5 \mathrm{~mm}$ HEPES, $5 \mathrm{~mm}$ MES, and 116 $\mathrm{mm} \mathrm{NaCl}, 116 \mathrm{~mm} \mathrm{LiCl}$, or $116 \mathrm{~mm} \mathrm{KCl}$, as indicated, with a $\mathrm{pH}$ adjusted to the indicated levels using $1 \mathrm{~m} \mathrm{NaOH}, \mathrm{KOH}$, or $\mathrm{LiOH}$ as appropriate. Oocyte recordings were done in a modified RC-Z3 $250 \mu$ l oocyte recording chamber (Warner Instruments). The solution exchange rate in the recording chamber was $\sim 1 \mathrm{ml} / \mathrm{s}$. ASIC current properties ( $\mathrm{pH}$-dependent activation and steady-state desensitization) were assessed as described previously (Sherwood and Askwith, 2009). Proton-gated current evoked in experimental conditions was always flanked by saturating $\mathrm{pH}$ applications to evoke maximal current ( $\mathrm{pH} 4.5$ unless otherwise noted). For quantification, peak current amplitude in experimental conditions was normalized to the average of the flanking maximal current amplitudes to minimize the impact of potential tachyphylaxis of proton-gated current. Big Dynorphin was synthesized by EZBiolab. Purified PCTX1 was purchased from Peptides International.

Oocyte data analysis. Data were analyzed using the Axon Clampfit 9.0 software. To measure the rate of channel desensitization, the decay phase of current was fitted to a single-exponential equation: $I=k_{0}+k_{1} \times$ $e^{-t / \tau_{\mathrm{d}}}$, and the tau of inactivation $\left(\tau_{\text {inact. }}\right)$ was calculated. Acid-induced sustained current was measured at the plateau phase of decay at least $20 \mathrm{~s}$ after application of pH 5.0 and normalized to peak current amplitude. For $\mathrm{pH}$-dependent activation and steady-state desensitization, the $\mathrm{pH}_{0.5}$ was calculated by fitting the data from individual oocytes using the following equation: $I / I_{\mathrm{pH} \text { max }}=1 /\left\{1+\left(\mathrm{EC}_{50} /\left[\mathrm{H}^{+}\right]\right)^{n}\right\}=1 /\left\{1+10^{n}(\mathrm{pH}-\mathrm{pH} 0.5)\right\}$, where $n$ is the Hill coefficient and $\mathrm{EC}_{50}$ and $\mathrm{pH}_{0.5}$ are the proton concentration and $\mathrm{pH}$-yielding half of the saturating peak current amplitude $\left(I_{\mathrm{pH} \max }\right)$. The $\mathrm{pH}_{\max }$ was determined by the application of $\mathrm{pH} 5.0$ from a holding $\mathrm{pH}$ of 7.9 (unless otherwise noted). The $\mathrm{EC}_{50}$ for Big Dynorphin was calculated by fitting the data from individual oocytes using the following equation: $I / I_{\max }=1 /\left\{1+\left(\mathrm{EC}_{50} / \text { [peptide] }\right)^{n}\right\}$, where $n$ is the Hill coefficient and $\mathrm{EC}_{50}$ is the peptide concentration inducing half of the saturating peptide effect $\left(I_{\max }\right)$. Relative cation permeabilities for ASICs expressed in oocytes were determined using the following equation: $\Delta E_{\text {rev }}=E_{\mathrm{rev}(\mathrm{x})}-E_{\mathrm{rev}\left(\mathrm{Na}^{+}\right)}=(R T / F) \ln \left\{\mathrm{P}_{\mathrm{x}}[\mathrm{X}]_{\mathrm{o}} / \mathrm{P}_{\mathrm{Na}^{+}}\left[\mathrm{Na}^{+}\right]_{\mathrm{o}}\right\}$, where $E_{\mathrm{rev}(\mathrm{x})}$ and $E_{\mathrm{rev}\left(\mathrm{Na}^{+}\right)}$are the experimentally determined reversal potentials of cation " $\mathrm{x}$ " and $\mathrm{Na}^{+}$, respectively; $[\mathrm{X}]_{\mathrm{o}}$ and $\left[\mathrm{Na}^{+}\right]_{\mathrm{o}}$ are the extracellular concentrations of cation $\mathrm{x}$ and $\mathrm{Na}^{+}$; and the constants $R, T$, and $F$ have their standard meanings. Statistical analysis was done with the two-tailed Student's $t$ test (paired or unpaired data as indicated) or ANOVA with post hoc Bonferroni's multiple comparison test as indicated in the figure legends. A $p$ value $<0.05$ was considered significant.

Chinese hamster ovary cell transfection and calcium permeability experiments. The whole-cell patch-clamp technique was used to measure calcium permeability of acid-evoked current in Chinese hamster ovary $(\mathrm{CHO})$ cells transiently transfected with green fluorescent protein (GFP), mouse ASIC1a, and one of the following: mouse ASIC2b, mouse ASIC2a, or vector only (Hoagland et al., 2010). Briefy, trypsinized CHO cells $\left(\sim 10^{7}\right.$ cells) were suspended in $0.4 \mathrm{ml}$ of electroporation solution (120 mM KCl, 25 mm HEPES buffer, $10 \mathrm{~mm} \mathrm{~K}_{2} \mathrm{HPO}_{4}, 10 \mathrm{~mm} \mathrm{KH_{2 }} \mathrm{PO}_{4}, 2$ mM $\mathrm{MgCl}_{2}, 0.15 \mathrm{~mm} \mathrm{CaCl}_{2}, 5$ mM EGTA, and 2 mm MgATP, pH 7.6) and mixed with $20 \mu \mathrm{g}$ of total plasmid DNA containing ASIC expression vectors (or empty pcDNA3.1 vector as indicated) and $\mathrm{pEGFP-C1}$ vector (Clontech) at a 1:1 ratio. Cells were electroporated with the Gene Pulser Xcell system (Bio-Rad) and plated at a density of 35 cells $/ \mathrm{mm}^{2}$ onto 10 $\mathrm{mm}$ coverslips in a $35 \mathrm{~mm}$ culture dish. Cells were used for patch clamping 2-3 d after transfection. Transfected cells were identified by expression of GFP. Data were collected at $5 \mathrm{kHz}$ using an Axopatch 200B amplifier, Digidata 1322A, and Clampex 9.0 (Molecular Devices). Extracellular solutions contained either $160 \mathrm{~mm} \mathrm{NaCl}$ or $80 \mathrm{~mm} \mathrm{CaCl}_{2}$ with 20 mM HEPES buffer and $10 \mathrm{~mm}$ glucose. The $\mathrm{pH}$ was adjusted with $\mathrm{NaOH}$ or $\mathrm{Ca}(\mathrm{OH})_{2}$ as appropriate. The intracellular pipette solution ( $\left.\mathrm{pH} 7.4\right)$ contained $160 \mathrm{~mm} \mathrm{NaCl}, 10 \mathrm{~mm}$ HEPES, and $10 \mathrm{~mm}$ EGTA. The pipette solution was allowed to dialyze with cytosolic contents for at least $5 \mathrm{~min}$ after whole-cell access was gained before ion permeability was measured. The membrane potential was held constant at $-50 \mathrm{mV}$ between voltageramp protocols. ASIC current was evoked by application of acidic extracellular solutions ( $\mathrm{pH} 5.3$ ), and a voltage ramp $(-150$ to $50 \mathrm{mV})$ was initiated immediately, before the current decayed into the plateau phase. To isolate background conductance, an identical voltage ramp was performed before and after ASIC activation at holding pH 7.6. Mean background conductance was subtracted from conductance after acid application, and data were fitted to a linear equation to determine the reversal potential of ASIC current. Junction potentials of sodium and calcium containing extracellular solutions $(-0.4$ and $+3.4 \mathrm{mV}$, respectively) were corrected post hoc. $P_{\mathrm{Na}} / P_{\mathrm{Ca}}$ was calculated from the change in reversal potentials when $\mathrm{Na}^{+}$was replaced with $\mathrm{Ca}^{2+}$ in the extracellular solution using the following equations: $\Delta E_{\mathrm{rev}}=E_{\mathrm{rev}, \mathrm{Na}}-E_{\mathrm{rev}, \mathrm{Ca}}=$ $(R T / F) \ln \left(P_{\mathrm{Na}}\left[\mathrm{Na}^{+}\right]_{\mathrm{o}} / 4 P_{\mathrm{Ca}}{ }^{\prime}\left[\mathrm{Ca}^{2+}\right]_{\mathrm{o}}\right)$ and $P_{\mathrm{Ca}}{ }^{\prime}=P_{\mathrm{Ca}} /\left(1+e^{E F / R T}\right)$, where the universal gas constant $(R)$, Faraday constant $(F)$, and temperature $(T)$ have their standard meanings. After the voltage ramp, zinc modulation $\left(0.3 \mathrm{mM} \mathrm{ZnCl}_{2}\right)$ of proton-gated current was measured to ensure appropriate heteromeric channels were expressed in the recorded $\mathrm{CHO}$ cells.

Culture of cortical and hippocampal neurons. Primary hippocampal and cortical neuron cultures were prepared using previously published methods with some minor alterations (Askwith et al., 2004). Briefly, hippocampi and cortices were dissected from postnatal day $0-1$ pups, freed from extraneous tissue, and cut into pieces. Dissected tissue was transferred into Leibovitz's L-15 medium containing $0.25 \mathrm{mg} / \mathrm{ml}$ bovine serum albumin and $0.38 \mathrm{mg} / \mathrm{ml}$ papain and incubated for $15 \mathrm{~min}$ at $37^{\circ} \mathrm{C}$ with $95 \% \mathrm{O}_{2}-5 \% \mathrm{CO}_{2}$ gently blown over the surface of the medium. After incubation, the dissected tissue was washed three times with mouse M5-5 medium (Earle's minimal essential medium with 5\% fetal bovine serum, $5 \%$ horse serum, $0.4 \mathrm{~mm}$ L-glutamine, $16.7 \mathrm{~mm}$ glucose, $5000 \mathrm{U} / \mathrm{l}$ penicillin, $50 \mathrm{mg} / \mathrm{l}$ streptomycin, $2.5 \mathrm{mg} / \mathrm{l}$ insulin, $16 \mathrm{~nm}$ selenite, and 1.4 $\mathrm{mg} / \mathrm{l}$ transferrin) and triturated. Dissociated cells were then centrifuged for $4.5 \mathrm{~min}$ at $730 \mathrm{rpm}$, and M5-5 medium was aspirated. Cells were resuspended in supplemented Neurobasal-A medium (1\% B27 supplement containing anti-oxidants, $1 \%$ B27supplement minus antioxidants, $0.5 \mathrm{~mm}$ L-glutamine, $0.5 \mathrm{mg} / \mathrm{ml}$ gentamycin, $2.5 \mathrm{mg} / \mathrm{l}$ insulin, $16 \mathrm{~nm}$ selenite, and $1.4 \mathrm{mg} / \mathrm{l}$ transferrin). Cells were plated in 24 -well 
plates containing $10 \mathrm{~mm}$ poly-D-lysine-coated glass coverslips at a density of $5 \times 10^{4}$ cells per well. After $48-72 \mathrm{~h}, 10 \mu \mathrm{M}$ cytosine $\beta$-Darabinofuranoside was added. Neurons were maintained at $37^{\circ} \mathrm{C}$ with $5 \% \mathrm{CO}_{2}$ for $14-21 \mathrm{~d}$ before experiments were performed.

Whole-cell patch clamp on primary neurons. To record ASICdependent current, neurons were perfused with extracellular solution at varying $\mathrm{pH}$ values. The extracellular solution contained $140 \mathrm{~mm} \mathrm{NaCl}$, $5.4 \mathrm{~mm} \mathrm{KCl}, 10 \mathrm{~mm}$ HEPES buffer, $2 \mathrm{~mm} \mathrm{CaCl}_{2}, 1 \mathrm{~mm} \mathrm{MgCl}$, $5.55 \mathrm{~mm}$ glucose, $10 \mathrm{~mm}$ MES buffer, $10 \mu \mathrm{M}$ 6-cyano-7-nitroquinoxaline-2,3dione (CNQX), $50 \mu \mathrm{M}$ D-2-amino-5-phosphonovaleric acid, $30 \mu \mathrm{M}$ bicuculline, and $500 \mathrm{~nm}$ tetrodotoxin. Certain extracellular solutions also contained $10 \mathrm{~mm} \mathrm{BaCl}, 0.3 \mathrm{~mm} \mathrm{ZnCl}$, or $50 \mathrm{~nm}$ PcTX1 (purified peptide) as indicated. The $\mathrm{pH}$ was adjusted with $1 \mathrm{~N} \mathrm{NaOH}$. Patch electrodes $(2-4 \mathrm{M} \Omega)$ were fire polished with a microforge (Narishige). The intracellular pipette solution contained $121 \mathrm{~mm} \mathrm{KCl}, 10 \mathrm{~mm} \mathrm{NaCl}, 2 \mathrm{~mm}$ $\mathrm{MgCl}_{2}, 5 \mathrm{~mm}$ EGTA, $10 \mathrm{~mm}$ HEPES, $2 \mathrm{~mm} \mathrm{Mg-ATP}$, and $300 \mu \mathrm{m}$ $\mathrm{Na}_{3} \mathrm{GTP}, \mathrm{pH}$ 7.25. The membrane potential was held constant at -70 $\mathrm{mV}$. Data were collected at $5 \mathrm{kHz}$ using an Axopatch 200B amplifier, Digidata 1322A, and Clampex 9 (Molecular Devices). Neurons were superfused continuously with the extracellular solution from gravity-fed perfusion pipes at a flow rate of about $1 \mathrm{ml} / \mathrm{min}$. Perfusion pipes were placed $250-300 \mu \mathrm{m}$ away from cells, and flow was directed toward the recorded cells to ensure fast solution exchange. For normalization, maximal acid-gated current was evoked by the exogenous application of $\mathrm{pH}$ 6.0 from a holding $\mathrm{pH}$ of 7.9. Typically, three to four applications of $\mathrm{pH}$ 6.0 solution were required before acid-evoked peak current amplitude stabilized and experimental conditions were tested. Peak current amplitude was normalized to the average peak current amplitude of flanking $\mathrm{pH}$ 6.0-evoked current.

RNAi design and analysis. Anti-mouse ASIC2b small hairpin RNA (shRNA) was designed using Oligoengine2.0 software (Oligoengine). The mouse ASIC2b coding sequence was analyzed, and a 19-nucleotide (19-nt) sequence, tgaccgtgtgcaacaacaa, corresponding to the ASIC2bspecfic splice variant sequence (starting at nucleotide position 397) was selected. Two complimentary 60-mer DNA oligonucleotides containing BgIII and HINDIII restriction cloning sites, ASIC2b 19-nt sense and antisense sequence, and a hairpin-promoting element were purchased from Oligoengine. The 60-mer strands were annealed together and cloned in a pSUPERgfp/neo expression plasmid according to the manufacturer's instructions (Oligoengine). Anti-ASIC2b shRNA-expressing plasmid was prepared from bacteria using Midiprep kits (Qiagen). All inserts were sequenced by the Plant-Microbe Genomics facility at The Ohio State University (Columbus, OH). Either the anti-ASIC2b shRNAexpressing plasmid or pSUPERgfp/neo was transfected into CHO cells along with mouse ASIC2b, ASIC2a, or ASIC1a (at a 3:2 ratio). Cells were allowed to grow for $2 \mathrm{~d}$ after transfection and harvested for quantitative RNA analysis.

RNA was isolated from transfected CHO cells using the RNeasy Mini kit (Qiagen) according to the manufacturer's instructions. RNA was treated with the DNA-free kit (Ambion) to destroy possible contaminating genomic DNA. cDNA was then made from DNase-treated RNA using reverse transcription and SuperScript III Reverse Transcriptase (Invitrogen), Oligo(dT)12-18, 10 mm dNTP Mix, and RNaseOUT Recombinant RNase Inhibitor (Invitrogen). For each sample, 50 ng of RNA was used in the cDNA synthesis reaction, and a "no-RT" reaction lacking reverse transcriptase was performed to produce the template for the no-RT control experiments. Real-time PCR was performed using the Power SYBR Green PCR Master Mix (Applied Biosystems) on a StepOnePlus Real Time PCR System using StepOne software (Applied Biosystems). Reactions were set up in triplicate. Per well, $20 \mu \mathrm{l}$ reactions consisted of $10 \mu \mathrm{l}$ of $2 \times$ Power SYBR Green Master Mix, $7.8 \mu \mathrm{l}$ of DEPC-treated DNase, RNase-free water (Invitrogen), $0.6 \mu$ l of each forward and reverse primer at $10 \mu \mathrm{M}$ concentration (Integrated DNA Technologies), and $1 \mu \mathrm{l}$ of diluted cDNA ( 1 part cDNA to 5 parts total volume). Final concentrations of reaction components were $1 \times$ Power SYBR Green Master Mix and $300 \mathrm{~nm}$ of each primer. Primers used include the following: mouse $\beta$-actin forward $5^{\prime}$-tacagcttcaccaccacagc- $3^{\prime}$ and reverse $5^{\prime}$-tctccagggaggaagaggat- $3^{\prime}$; mouse glyceraldehyde 3 -phosphate dehydrogenase (GAPDH) forward $5^{\prime}$-acccagaagactgtggatgg- $3^{\prime}$ and reverse $5^{\prime}$-ggatgcagggatgatgttct- $3^{\prime}$; mouse ASIC2b forward $5^{\prime}$ tgtcaccgtgtgcaacaac- $3^{\prime}$ and reverse $5^{\prime}$-cagcagcagtcctagccagt- $3^{\prime}$; mouse ASIC2a forward $5^{\prime}$-aaaccgaagcagttcagcat- $3^{\prime}$ and reverse $5^{\prime}$-gccccttgaacttgcagtag- $3^{\prime}$; mouse ASICla forward 5' -ctgtaccatgctggggaact- $3^{\prime}$ and reverse $5^{\prime}$-gctgcttttcatcagccatc- $3^{\prime}$. Cycling conditions consisted of an initial activation at $95^{\circ} \mathrm{C}$ for $10 \mathrm{~min}$, followed by 40 cycles of two-step PCR; $95^{\circ} \mathrm{C}$ for $15 \mathrm{~s}, 60^{\circ} \mathrm{C}$ for $1 \mathrm{~min}$, followed by a melt curve analysis. Cycle threshold was taken at $0.2 \Delta \mathrm{Rn}$. Melt-curve analysis indicated single products. All reactions were performed in triplicate along with "nocDNA" controls (in which water was added instead of cDNA). A no-RT control reaction was always done with each primer set on each batch of cDNA. Efficiency measurements were performed with all primer sets, and primers displayed efficiencies calculated to be within 0.1 of each other using the equation $e=10^{(-1 / \text { slope })}-1$. Data were normalized to $\beta$-actin expression to determine the $\Delta \mathrm{Ct}$ according to the manufacturer's instructions. Relative RNA expression was determined using the $\Delta \Delta \mathrm{Ct}$ method. To asses the effectiveness of anti-ASIC2b shRNA, CHO cells were cotransfected with either anti-ASIC2b shRNA-expressing plasmid or empty pSUPER plasmid and one of the following: mASICla, mASIC2a, or mASIC2b plasmid. Compared with pSUPER control, the anti-ASIC2b shRNA-expressing plasmid reduced ASIC2b RNA levels to $35.9 \pm 3.8 \%(p=0.002$ compared with GAPDH) but did not reduce GAPDH, mASIC1a, or mASIC2a RNA levels (GAPDH RNA, $113.6 \pm$ $14.5 \%$ vs control; ASICla RNA, $140 \pm 15 \%, p=0.2$ compared with GAPDH; ASIC2a RNA, $135.5 \pm 5.9 \%, p=0.08$ compared with GAPDH; $n=4$ transfections for all groups).

Transfection of primary neurons. Wild-type hippocampal neurons were transfected with empty pSUPERgfp/neo vector (control) or anti-ASIC2b shRNA-containing pSUPERgfp/neo vector (see above) at the time of culture, before plating. Briefly, dissociated hippocampal cells were split into two groups from the same preparation (3-4 million cells each group), suspended in $100 \mu \mathrm{l}$ of Nucleofector solution from the Basic Nucleofector kit (Amaxa Biosystems), and mixed with $3 \mu \mathrm{g}$ of plasmid DNA. Hippocampal cells were electroporated with the Nucleofector II (program O-05; Amaxa) and plated on poly-D-lysine coverslips in 24-well dishes at a density of 500,000-1,000,000 cells per well in Neurobasal-A medium (see above). Cytosine $\beta$-D-arabinofuranoside (10 $\mu \mathrm{M})$ was added as before. Neurons were used for patch clamping (single cells) or qRT-PCR analysis (whole coverslips) from 14 to $20 \mathrm{~d}$ in culture. Transfected cells were identified for patching by GFP fluorescence and selected for recording using a TE2000-S epifluorescent microscope (Nikon).

Acid-induced neuronal damage assays. At 14-17 d in culture, cortical neurons were randomly divided into designated experimental groups (see Fig. 8). Neurobasal medium was removed before washing cells two times with ECF solution $(140 \mathrm{~mm} \mathrm{NaCl}, 5.4 \mathrm{~mm} \mathrm{KCl}, 25 \mathrm{~mm}$ HEPES buffer, $20 \mathrm{~mm}$ glucose, $\left.1.3 \mathrm{~mm} \mathrm{CaCl}_{2}, 1.0 \mathrm{~mm} \mathrm{MgCl}_{2}\right)$ at $\mathrm{pH} 7.6(\mathrm{pH}$ adjusted with $1 \mathrm{~N} \mathrm{NaOH}$ ). Cells were then washed with $\mathrm{pH}$ 7.6 ECF inhibitor solution containing $10 \mu \mathrm{M}$ Dizocilpine (MK-801), $20 \mu \mathrm{M}$ CNQX, $5 \mu \mathrm{m}$ nimodipine, and $500 \mathrm{~nm}$ tetrodotoxin. Specific acidosis interventions were performed as described in the presence or absence of $10 \mathrm{~mm} \mathrm{Ba}^{2+}$ using ECF with inhibitors (Xiong et al., 2004; Gao et al., 2005; Sherwood and Askwith, 2009). Within each culture, three to twelve different wells were used for a given intervention. After acidosis interventions, cells were washed two times with pH 7.6 ECF without inhibitors, and fresh Neurobasal culture medium was returned to cultures. Neurons were allowed to recover for $18-24 \mathrm{~h}$ at $37^{\circ} \mathrm{C}$ with $5 \% \mathrm{CO}_{2}$. Acid-induced damage was assessed after the recovery period using the Vybrant MTT cell proliferation assay kit (Invitrogen) as per the manufacturer's instructions, scaled for use in 24-well plate cultures. Briefly, at $24 \mathrm{~h}$ after intervention, cells were incubated in fresh Neurobasal culture medium containing $1.2 \mathrm{~mm}$ 3-(4,5-dimethylthiazol-2-yl)-2,5-diphenyltetrazolium bromide (MTT) for $4 \mathrm{~h}$ at $37^{\circ} \mathrm{C}$ with $5 \% \mathrm{CO}_{2}$. After MTT treatment, medium was removed and cells were treated with DMSO $\left(10 \mathrm{~min}\right.$ at $37^{\circ} \mathrm{C}$ with $\left.5 \% \mathrm{CO}_{2}\right)$ to solubilize formazan produced as a result of MTT metabolism. DMSO extract from each well $(100 \mu \mathrm{l})$ was collected on a 96-well plate, and formazan content was determined by reading absorbance at $540 \mathrm{~nm}$. To determine background absorbance, $100 \mu \mathrm{l}$ samples from empty wells treated with Neurobasal-MTT medium and DMSO were also read. The effect of acid 
treatment on neurons was measured by subtracting average background absorbance from individual well data and normalizing individual well data to the average absorbance from the "No Acid" control group in the absence of barium. Data from individual wells were then averaged so that one neuronal culture yielded one $n$ for a given acidosis intervention. " $\%$ Acid-Induced Damage" is the percentage decrease in absorbance of "Acid"-treated groups compared with No Acid groups in the presence or absence of barium.

\section{Results}

\section{ASIC2b/1a channels are sensitive to barium and TEA}

To determine whether ASIC2b affects the ASIC1a-dependent current, we analyzed proton-gated currents in Xenopus oocytes coexpressing mouse ASIC2b with mouse ASICla and compared them with currents elicited from oocytes expressing either subunit alone. Oocytes expressing ASIC1 a showed proton-gated currents when the extracellular $\mathrm{pH}$ was rapidly decreased (Fig. 1A). No proton-gated currents were observed when ASIC2b was expressed alone, and expression of ASIC1a with ASIC2b resulted in proton-gated currents that appeared grossly similar to ASIC1a homomeric channels (Fig. 1A). To identify compounds that could distinguish ASIC2b/1a heteromeric channels from ASIC1a homomeric channels, we tested TEA. Previous studies showed that ASIC2a channels with a mutation within the pore (G430V) were inhibited by the classic nonspecific inhibitor of potassium channels, TEA (Adams et al., 1999). Since TEA inhibits mutant ASIC2a channels, we reasoned that ASIC2a- or ASIC2bcontaining heteromeric channels may also be sensitive to TEA. We found that proton-gated currents in oocytes expressing ASIC1a alone were not inhibited by $10 \mathrm{~mm}$ TEA (Fig. $1 B, C$ ). However, proton-gated currents in cells coexpressing ASIC2b or ASIC2a with ASIC1a were inhibited by TEA (Fig. $1 B, C$ ). Both ASIC2b/1a- and ASIC2a/1a-expressing cells showed equivalent concentration-dependent TEA inhibition at low millimolar concentrations, whereas ASIC1a showed inhibition only at higher concentrations of TEA (50 mM) (Fig. 1D). Although TEA does not distinguish between ASIC2a- or ASIC2b-containing heteromeric channels, it does indicate that ASIC2b/1a heteromeric channels produce proton-activated currents on the plasma membrane that display pharmacologically distinct properties from ASICla homomeric channels.

To further determine whether ASIC2b/1a currents could be distinguished from ASIC1a or ASIC2a/1a currents, we tested barium, another nonspecific inhibitor of potassium channels (Hurst et al., 1995; Harris et al., 1998; Jiang and MacKinnon, 2000). ASIC1a was unaffected by $10 \mathrm{~mm}$ barium, whereas current from ASIC2b/1a heteromeric channels was appreciably inhibited (Fig. $1 B, C)$. Interestingly, barium had a significantly greater effect on ASIC2b/1a current compared with either ASIC1a homomeric or ASIC2a/ 1a heteromeric current (percentage inhibition was $2.2 \pm$ $2.0 \%$ for ASIC1a, $8.4 \pm 1.2 \%$ for ASIC $2 \mathrm{a} / 1 \mathrm{a}$, and $23.9 \pm 3.1 \%$ for ASIC2b/1a; $p<0.01$ compared with ASIC1a, $p<0.05$ compared with ASIC2a/1a, one-way ANOVA) (Fig. 1C). In addition, the concentration dependence of barium inhibition was significantly lower for ASIC2b/1a compared with ASIC1a or ASIC2a/1a, although all channels were sensitive to barium at high concentrations (Fig. 1E).

Extracellular TEA and barium inhibition of potassium channels occurs through a pore-blocking mechanism (Eaton and Brodwick, 1980; Taglialatela et al., 1991). Such ion channel pore blockers often show voltage-dependent inhibition, with inhibition decreasing as current nears the reversal potential, and no inhibition with outward current. TEA and barium inhibition of ASIC2b/1a currents was also voltage dependent as the effect of
A

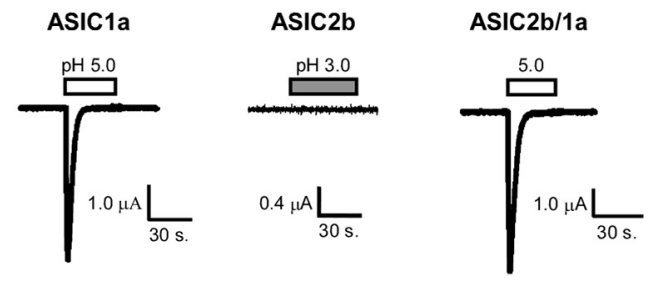

B
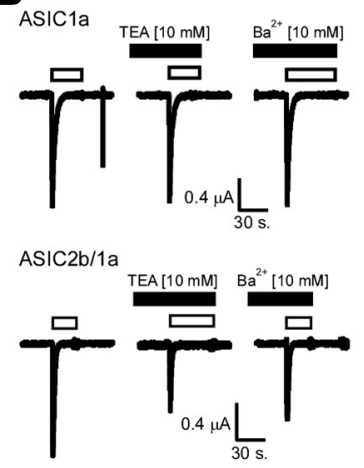

C

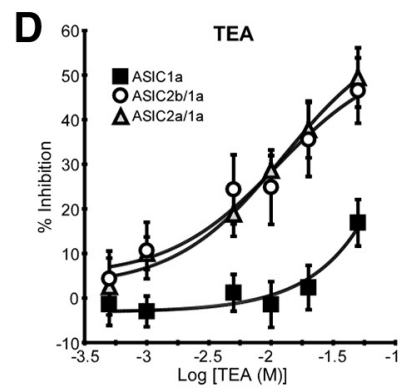

$E$
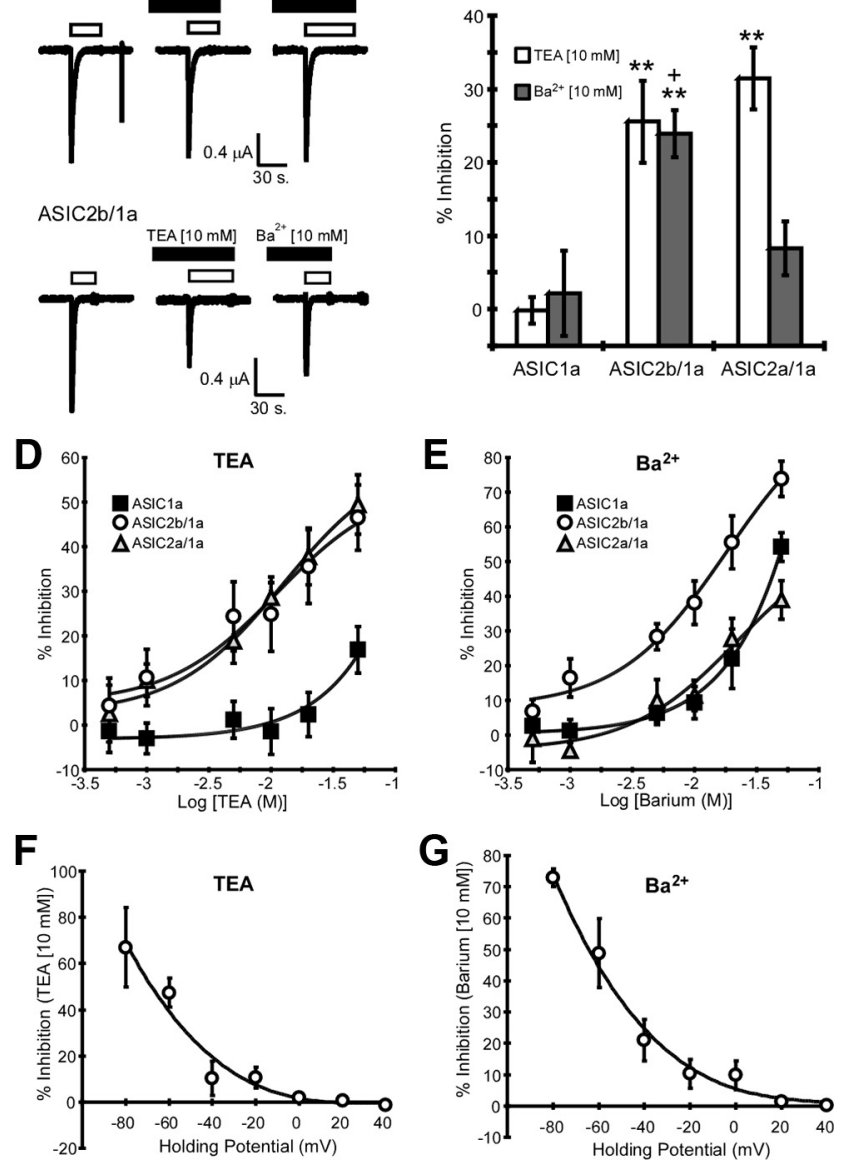

Figure 1. Coexpression of ASIC2b with ASIC1a changes the pharmacology of proton-gated currents. $A$, Representative trace of acid-evoked current from Xenopus oocytes expressing mouse ASIC1a, ASIC2b, or both. Bars above the trace show application of acidic solution (pH indicated). $\boldsymbol{B}$, Representative traces showing the effects of extracellular TEA and barium ions on ASIC1a (top) and ASIC2b/1a (bottom) current in oocytes. ASIC current was evoked by application of pH 4.5 (white bars) from a holding pH of 7.9. Black bar indicates application of extracellular solution containing $10 \mathrm{~mm}$ TEA or $\mathrm{Ba}^{2+}$ before and during acid application. C, Quantification of TEA or $\mathrm{Ba}^{2+}$ inhibition. \% Inhibition Difference in current amplitude in the presence of TEA or barium compared with control current amplitude. ${ }^{* *} p<0.01$, compared with the corresponding ASIC1a group; $+p<0.05$, compared with the corresponding ASIC2a/1a group with ANOVA (1-way). $n=3-6$ for ASIC1a, $n=4-7$ for $\mathrm{ASIC} 2 \mathrm{~b} / 1 \mathrm{a}$, and $n=3-5$ for ASIC2a/1a. Note that results with ASIC1a are not significantly different from zero. $\boldsymbol{D}, \boldsymbol{E}$, Concentration dependence of TEA (D) and Ba ${ }^{2+}(\boldsymbol{E})$ inhibition of ASIC current. TEA or $\mathrm{Ba}^{2+}$ was added at the indicated concentrations, and data were normalized to $\mathrm{pH}$ 4.5-evoked control current as before. $n=4$ for ASIC1a, $n=5$ for ASIC2b/1a, and $n=5$ for ASIC2a/1a. F, G, Voltage dependence for TEA $(\boldsymbol{F})$ and $\mathrm{Ba}^{2+}(\boldsymbol{G})$ inhibition of ASIC2b/1a current. Current was evoked in the presence of $10 \mathrm{~mm}$ TEA, $\mathrm{Ba}^{2+}$, or control at the indicated holding potentials, and \% Inhibition was determined as before $(n=3-4)$. Error bars are the SEM.

either compound was abolished at positive holding potentials (Fig. $1 F, G$ ). These results are consistent with a pore-blocking mechanism for ASIC2b/1a inhibition similar to that observed with extracellular TEA and barium inhibition of other ion channels. 


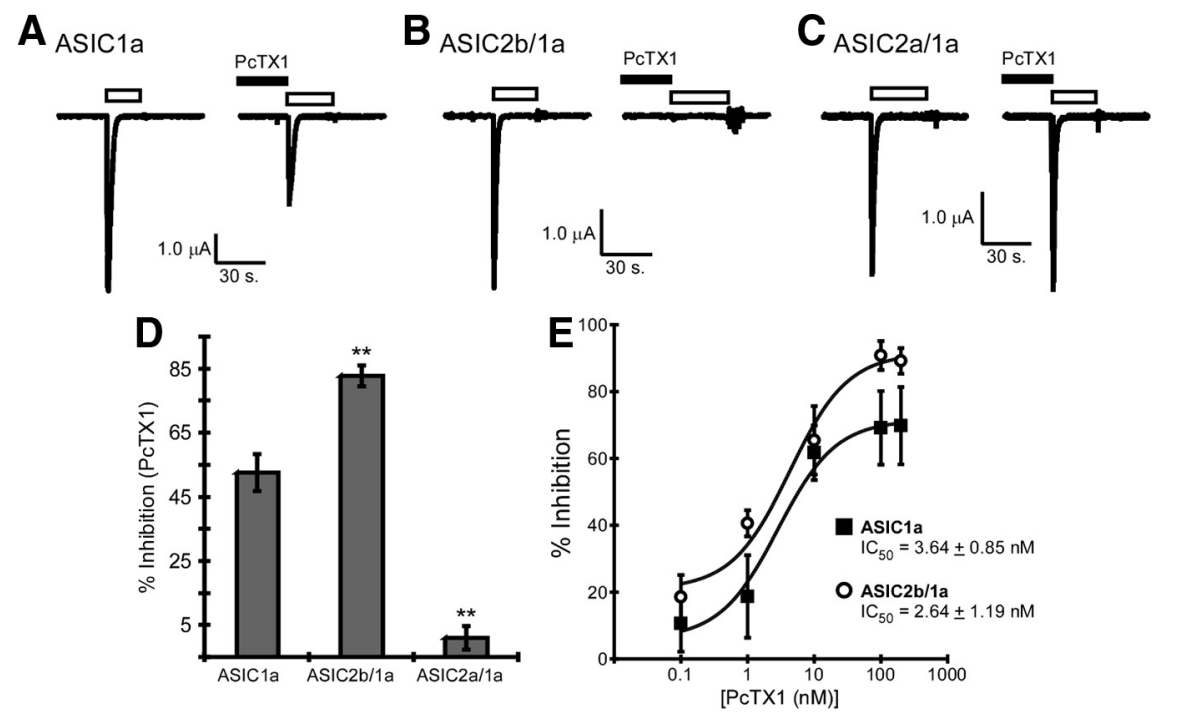

Figure 2. Psalmotoxin 1 inhibits ASIC2b/1a current. $\boldsymbol{A}$-C, Representative traces showing PCTX1 (0.2 $\mu \mathrm{m})$ effects on mouse ASIC1a $(\boldsymbol{A})$, ASIC2b/1a $(\boldsymbol{B})$, and ASIC2a/1a $(\boldsymbol{C})$ current in 0ocytes. Activation of ASIC current was achieved by applying pH 4.5 (white bar) from holding pH 7.9. The black bar indicates application of $0.2 \mu \mathrm{M}$ PCTX1 for $3 \mathrm{~min}$ before application of pH 4.5. D, Quantification of PCTX1 effect on ASIC current. \% Inhibition, Difference in current amplitude after PcTX1 treatment compared with maximal current amplitude in the absence of PCTX1. ${ }^{* *} p<0.01$, compared with ASIC1a group with ANOVA (1-way). $n=6$ for ASIC1a, $n=$ 7 for ASIC2b/1a, and $n=5$ for ASIC2a/1a. E, Concentration dependence of PcTX1 inhibition. PcTX1 was applied at the indicated concentrations, and ASIC current was measured as above. The $\mathrm{IC}_{50}$ shown is the average value calculated from individual cells $(n=$ 4-7 for ASIC1a and ASIC2b/1a). Error bars are the SEM.

\section{ASIC2b/1a channels are inhibited by PcTX1}

PcTX1 is a tarantula venom peptide that inhibits ASIC1a homomeric channels and has been used to prevent activation in vitro and in vivo (Escoubas et al., 2000; Xiong et al., 2004; Mazzuca et al., 2007; Pignataro et al., 2007; Coryell et al., 2008, 2009; Ziemann et al., 2008, 2009). PcTX1 is thought to be an ASIC1aspecific inhibitor and does not inhibit heteromeric channels, such as ASIC2a/1a (Escoubas et al., 2000, 2003; Chen et al., 2006; Salinas et al., 2006). To determine whether PcTX1 acts on ASIC2b/1a channels, oocytes expressing ASIC1a, ASIC2b/1a, or ASIC2a/1a were treated with PcTX1 before activation. As expected, ASIC1a homomers were inhibited by $0.2 \mu \mathrm{M}$ PcTX1 whereas ASIC2a/1a heteromers were not (Fig. 2A,C). Surprisingly, oocytes expressing ASIC2b/1a were also sensitive to PcTX1 (Fig. 2 B). In fact, PcTX1 inhibited ASIC2b/1a current by $82.0 \pm$ $3.2 \%$, which was significantly greater than its effect on ASIC1a current (52.6 $\pm 5.7 \%$; $p<0.001$, one-way ANOVA) (Fig. 2D). However, the $\mathrm{IC}_{50}$ for PcTX1 inhibition of ASIC1a homomeric and ASIC2b/1a heteromeric channels was not statistically different, suggesting both channels have equivalent affinities for the peptide (Fig. 2E). Because PcTX1 inhibits ASIC1a by enhancing steady-state desensitization and ASIC2b/1a channels showed greater inhibition with $0.2 \mu \mathrm{M}$ PcTX1, we reasoned that ASIC2b/1a channels may be more prone to undergo steady-state desensitization compared with ASIC1a (Chen et al., 2005).

\section{ASIC2b enhances steady-state desensitization}

Steady-state desensitization of ASIC is induced when the channels are exposed to mild decreases in $\mathrm{pH}$ that are not sufficient for maximal channel activation (Babini et al., 2002). PcTX1 acts by increasing the apparent proton sensitivity of steady-state desensitization and causing ASICla to desensitize at basal $\mathrm{pH} 7.4$, which normally does not induce desensitization (Chen et al., 2005). Thus, the increased PcTX1-mediated inhibition of ASIC2b/1a could be indicative of intrinsic differences in steady- state desensitization. Steady-state desensitization is experimentally observed as a decrease in $\mathrm{pH}$ 5.0-evoked peak current amplitude directly after exposure (2 $\mathrm{min})$ to a mildly acidic "conditioning" pH (Fig. $3 A$ ). For example, when oocytes expressing ASICla alone are conditioned at $\mathrm{pH}$ 7.4, steady-state desensitization of $\mathrm{pH} 5.0$ evoked current is not induced $\left(I / I_{\max }=\right.$ $98.6 \pm 9.7 \% ; p=0.89$ compared with conditioning $\mathrm{pH}$ 7.9). But exposing cells to $\mathrm{pH} 7.2$ induces steady-state desensitization and reduces $\mathrm{pH} 5.0$-evoked current to $62.4 \pm 8.8 \%$ of maximal current $(p=$ 0.01 compared with conditioning $\mathrm{pH}$ 7.9) (Fig. 3B). In oocytes expressing ASIC2b/ 1a, enhanced steady-state desensitization was observed such that $\mathrm{pH}$ 5.0-evoked current was reduced even at a conditioning $\mathrm{pH}$ of $7.4(78.6 \pm 4.0 \% ; p<0.001$ compared with conditioning $\mathrm{pH}$ 7.9) (Fig. $3 A)$. A more detailed analysis revealed that the $\mathrm{pH}_{50}$ of steady-state desensitization was $7.28 \pm 0.02$ for ASIC2b/1a $(n=$ $10)$ and $7.18 \pm 0.1$ for ASICla $(n=4 ; p=$ 0.01 ) (Fig. 3B). Thus, the presence of ASIC2b caused a shift in the $\mathrm{pH}$ dependence of steady-state desensitization such that less acidic $\mathrm{pH}$ values induced desensitization.

We also examined other intrinsic properties of ASIC2b/1a heteromeric channels. Acid-dependent sustained current and inactivation rate after activation were not different in cells expressing ASIC2b/1a versus ASIC1a alone [ $\tau_{\text {inactivation: }}$ ASIC1a, $3.16 \pm$ $0.18 \mathrm{~s}(n=9) ;$ ASIC2b/1a, $2.60 \pm 0.43 \mathrm{~s}(n=11 ; p=0.283)$; percentage sustained current: ASIC1a, $0.44 \pm 0.11 \%(n=11)$; ASIC2b/1a, $1.16 \pm 0.64 \%(n=7 ; p=0.084)]$. The apparent proton sensitivity of activation was not different $\left[\mathrm{pH}_{50 \text { act. }}=\right.$ $6.54 \pm 0.04$ for ASIC1a $(n=4), \mathrm{pH}_{50 \text { act. }}=6.42 \pm 0.06$ for ASIC2b/1a $(n=5 ; p=0.16)]$ (Fig. 3C). These results are consistent with past reports assessing coexpression of ASIC2b with ASIC1a (Hesselager et al., 2004). Next, we examined monovalent cation permeability of ASIC1a and ASIC2b/1a channels (Fig. $3 D, E)$. The calculated ion permeability ratios for sodium and potassium were similar for ASIC1a and ASIC2b/1a $\left(\mathrm{P}_{\mathrm{K}^{+}} / \mathrm{P}_{\mathrm{Na}^{+}}=\right.$ $0.113 \pm 0.034$ for ASIC1a, $0.148 \pm 0.050$ for ASIC2b/1a; $p=$ 0.62 ). Yet, cells expressing ASIC2b/1a showed a reduced permeability for lithium $\left(\mathrm{P}_{\mathrm{Li}^{+}} / \mathrm{P}_{\mathrm{Na}^{+}}=1.022 \pm 0.105\right.$ for ASIC1a, $0.667 \pm 0.082$ for ASIC2b/1a; $p=0.04$ ). This provides additional evidence that ASIC2b forms novel heteromeric channels with ASIC1a that have unique pore features and is consistent with our results showing these channels are inhibited by both TEA and barium through a pore-blocking mechanism.

\section{ASIC2b/1a is permeable to calcium ions}

Currently, ASIC1a and human ASIC1b homomers are the only ASICs known to be appreciably permeable to calcium ions (Waldmann et al., 1997; Waldmann and Lazdunski, 1998; Bassler et al., 2001; Hoagland et al., 2010). The unique calcium permeability of ASIC1a has significant implications for its role in normal physiology, as well as mediating neuronal death in a variety of pathological conditions (Voilley, 2004; Xiong et al., 2004; Wemmie et al., 2006; Xiong et al., 2006; Xu and Duan, 2009). $\mathrm{Ca}^{2+}$ permeability was measured in $\mathrm{CHO}$ cells transiently transfected 
A
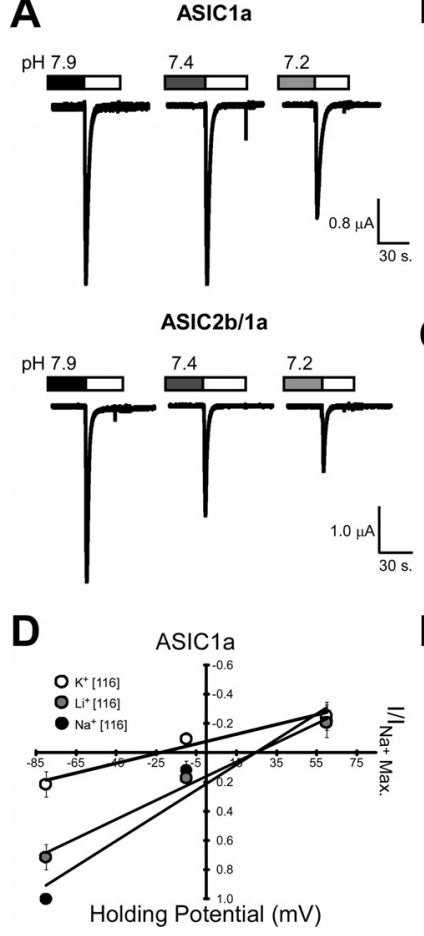

E

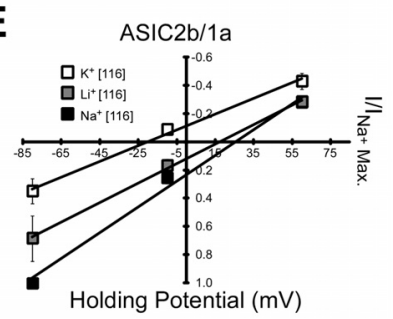

Figure 3. ASIC2b/1a channels show enhanced steady-state desensitization compared with ASIC1a homomeric channels. $\boldsymbol{A}$, Representative traces showing steady-state desensitization of acid-evoked currents from oocytes expressing ASIC1a (top) or ASIC2b/1a (bottom). Maximal acid-evoked current is shown left (white bar, pH 5.0) from holding pH 7.9 (black bar). Steadystate desensitization was induced by application of a conditioning $\mathrm{pH}$ solution (colored bars) for 2 min before application of $\mathrm{pH}$ 5.0. B, Quantification of the $\mathrm{pH}$ dependence for steady-state desensitization. ASIC current was evoked with pH 5.0 application after exposure to the test conditioning $\mathrm{pH}$ and normalized to $\mathrm{pH}$ 5.0-evoked current after $\mathrm{pH} 7.9$ conditioning $\left(/ / I_{\max }\right)$. $n=3-9$ for ASIC1a, and $n=5-13$ for ASIC2b/1a. C, Quantification of pH-dependent activation. Holding $\mathrm{pH}$ was maintained at 7.9, and peak current amplitude after application of the indicated test $\mathrm{pH}$ solutions was normalized to $\mathrm{pH}$ 5.0-evoked current amplitude $\left(/ / I_{\max }\right) \cdot n=$ 4-6 for ASIC1a, and $n=3-5$ for ASIC2b/1a. D, E, I-V relationships of ASIC1a (D) and ASIC2b/1a $(\boldsymbol{E})$ current in the presence of extracellular solutions containing $\mathrm{Na}^{+}, \mathrm{Li}^{+}, \mathrm{or} \mathrm{K}^{+}$at the indicated mm concentrations. Acid-evoked current amplitudes ( $\mathrm{pH}$ 5.0) in each cation solution were normalized to peak current amplitude in the $\mathrm{Na}^{+}$solution at $-80 \mathrm{mV}$ holding potential for

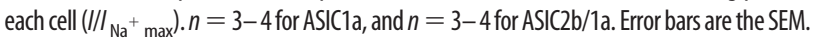

with ASIC1a, ASIC2b/1a, or ASIC2a/1a (Hoagland et al., 2010). As expected, current from all three channels showed a linear current-voltage relationship with a reversal potential near zero in extracellular solutions containing $160 \mathrm{~mm}$ sodium (Fig. 4A-C). When extracellular sodium was replaced with calcium, a large negative shift in the reversal potential was observed for ASIC2a/1a channels, whereas only a minor shift was observed for ASIC1a and ASIC2b/1a channels (Fig. 4A-C). This result suggested that ASIC2b/1a heteromeric channels are calcium permeable like ASIC1a homomeric channels. The relative permeability of $\mathrm{Na}^{+}$compared with $\mathrm{Ca}^{2+}\left(P_{\mathrm{Na}} / P_{\mathrm{Ca}}\right)$ was calculated from the change in reversal potentials between sodium- and calciumcontaining solutions (Fig. 4D). ASIC2a/la heteromeric channels had a $P_{\mathrm{Na}} / P_{\mathrm{Ca}}$ of $25.5 \pm 5.6(n=6)$, supporting previous studies showing that ASIC2a/1a channels posses little calcium permeability (Bassilana et al., 1997; Yermolaieva et al., 2004). The $P_{\mathrm{Na}} l$ $P_{\mathrm{Ca}}$ was $1.8 \pm 0.9(n=8)$ for ASIC1a and $4.1 \pm 1.4(n=6)$ for ASIC2b/1a, indicating both channels are permeable to calcium.

\section{ASIC2b/1a and modulation with extracellular zinc}

Previous work has shown that extracellular zinc ions modulate ASIC current in a subunit-dependent manner (Baron et al., 2001;
A

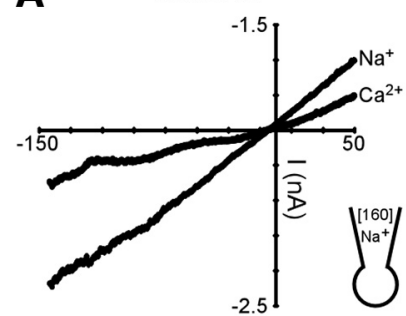

Holding Potential (mV)

C

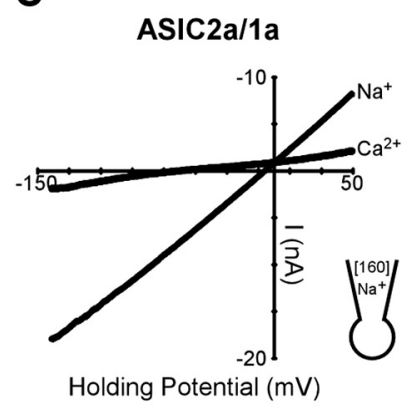

B

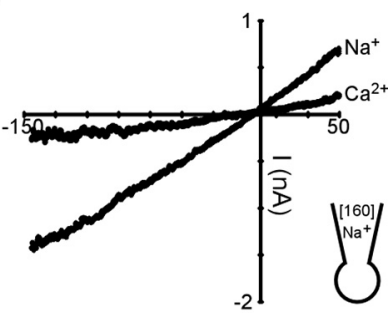

Holding Potential (mV)

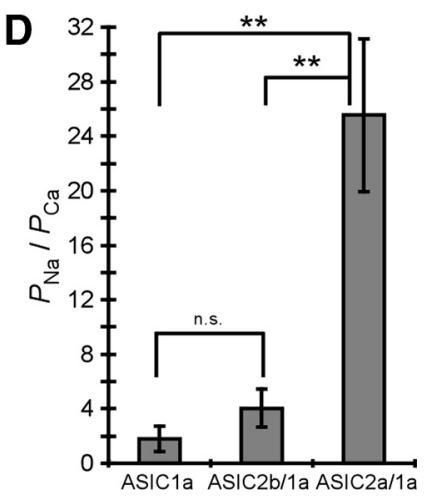

Figure 4. Calcium permeability of $\mathrm{ASIC} 2 \mathrm{~b} / 1 \mathrm{a}$ expressed in $\mathrm{CHO}$ cells. $\boldsymbol{A}-\boldsymbol{C}$, Representative I-V plots of ASIC1a (A), ASIC2b/1a (B), and ASIC2a/1a (C) expressed in CHO cells. Recordings were done using whole-cell patch clamp with extracellular solutions containing $160 \mathrm{~mm} \mathrm{NaCl}$ or $80 \mathrm{~mm} \mathrm{CaCl}$. The pipette solution contained $160 \mathrm{~mm} \mathrm{NaCl}$ as indicated in the diagrams. ASIC current was evoked by application of acidic ( $\mathrm{pH}$ 5.3) solution from a holding solution of $\mathrm{pH} 7.6$ The voltage ramp $(-150$ to $+50 \mathrm{mV})$ was applied during the transient phase of ASIC current. $D$, Quantification of the average sodium/calcium permeability ratios $\left(P_{\mathrm{Na}} / P_{\mathrm{Ca}}\right)$ for $\mathrm{CHO}$ cells expressing ASIC1a, ASIC2b/1a, and ASIC2a/1a $(n=6-8) .{ }^{* *} p<0.01$ with ANOVA (1-way). Error bars are the SEM.

Chu et al., 2004). Specifically, $\mathrm{Zn}^{2+}$ inhibits ASICla and ASIC2a/1a channels at nanomolar concentrations but potentiates ASIC2a and ASIC2a/1a heteromers at micromolar concentrations (Baron et al., 2001; Chu et al., 2004). Thus, $\mathrm{Zn}^{2+}$ has dual effects on some ASICs. We tested the effects of $0.3 \mathrm{~mm} \mathrm{Zn}^{2+}$ on oocytes expressing ASIC1a, ASIC2b/1a, and ASIC2a/1a (Fig. 5A). Both ASIC1a and ASIC2b/1a showed reversible inhibition with zinc, whereas ASIC2a/la was potentiated in the presence of 0.3 $\mathrm{mm} \mathrm{Zn}^{2+}$. Quantification revealed a $51.00 \pm 17.90 \%(n=8)$ increase in $\mathrm{pH} 4.5$-evoked current in the presence of $0.3 \mathrm{~mm}$ $\mathrm{Zn}^{2+}$ for ASIC2a/1a, a $41.20 \pm 6.38 \%$ decrease for ASIC1a $(n=$ 7 ), and a $19.68 \pm 3.93 \%$ decrease for ASIC2b/1a $(n=8)$ (Fig. $5 B)$. Thus, ASIC2b/1a heteromeric channels are not modulated by zinc in the same manner as ASIC2a/1a channels. Furthermore, the presence of ASIC2b attenuates zinc modulation as cells expressing ASIC2b with ASIC1a are less affected than cells expressing ASIC1a alone (Fig. $5 B)(p=0.01, t$ test). We also tested the effects of the zinc chelator TPEN as nominal concentrations of zinc can inhibit ASIC1a and ASIC2a/la heteromeric channels (Chu et al., 2004). TPEN significantly enhanced current for all three channels suggesting ASIC2b/1a, like ASIC1a and ASIC2a/1a, is inhibited by low nanomolar concentrations of zinc (Fig. $5 C$ ).

\section{ASIC2b enhances dynorphin modulation}

The opioid peptide Big Dynorphin limits steady-state desensitization of ASICla homomers and can enhance acidosis-induced neuronal death (Sherwood and Askwith, 2009). Because ASIC2b affects both PcTX1 inhibition and the $\mathrm{pH}$ dependence of steadystate desensitization, we tested Big Dynorphin modulation of 

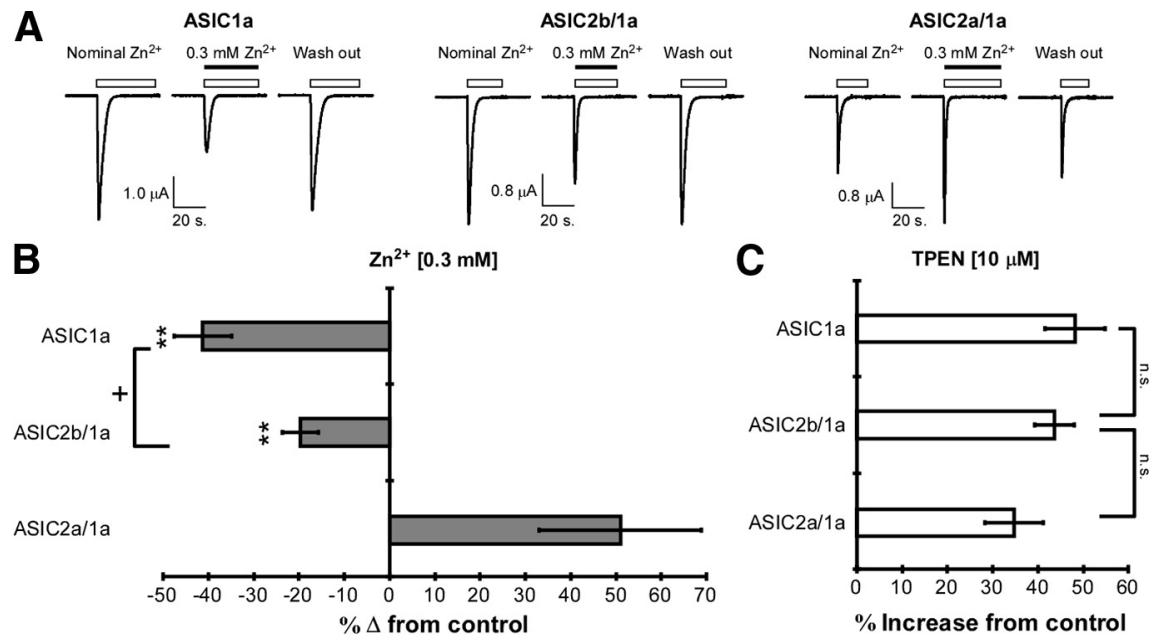

Figure 5. Zinc modulation of ASIC2b/1a channels. A, Representative traces showing effects of extracellular zinc on ASIC1a, $\mathrm{ASIC} 2 \mathrm{~b} / 1 \mathrm{a}$, and ASIC2a/1a expressed in 0ocytes. Currents were evoked by application of $\mathrm{pH} 4.5$ (white bars) from holding $\mathrm{pH} 7.9$ in the presence or absence of $0.3 \mathrm{~mm}$ zinc (black bars). B, Quantification of zinc effects on ASIC peak current amplitude. \% $\Delta$ from control, Difference in normalized peak current amplitude in the presence of zinc compared with control current amplitude. ${ }^{* *} p<$ 0.01 (ANOVA, 1-way), compared with ASIC2a/1a; $+p<0.05$ with Student's $t$ test (unpaired); $n=7-8$. C, The effect of extracellular TPEN $(10 \mu \mathrm{M})$ on ASIC currents. \% increase from control, Difference in normalized peak current amplitude in the presence of TPEN compared with control current amplitude. Significance was measured with ANOVA (1-way); $n=7-8$. Error bars are the SEM.

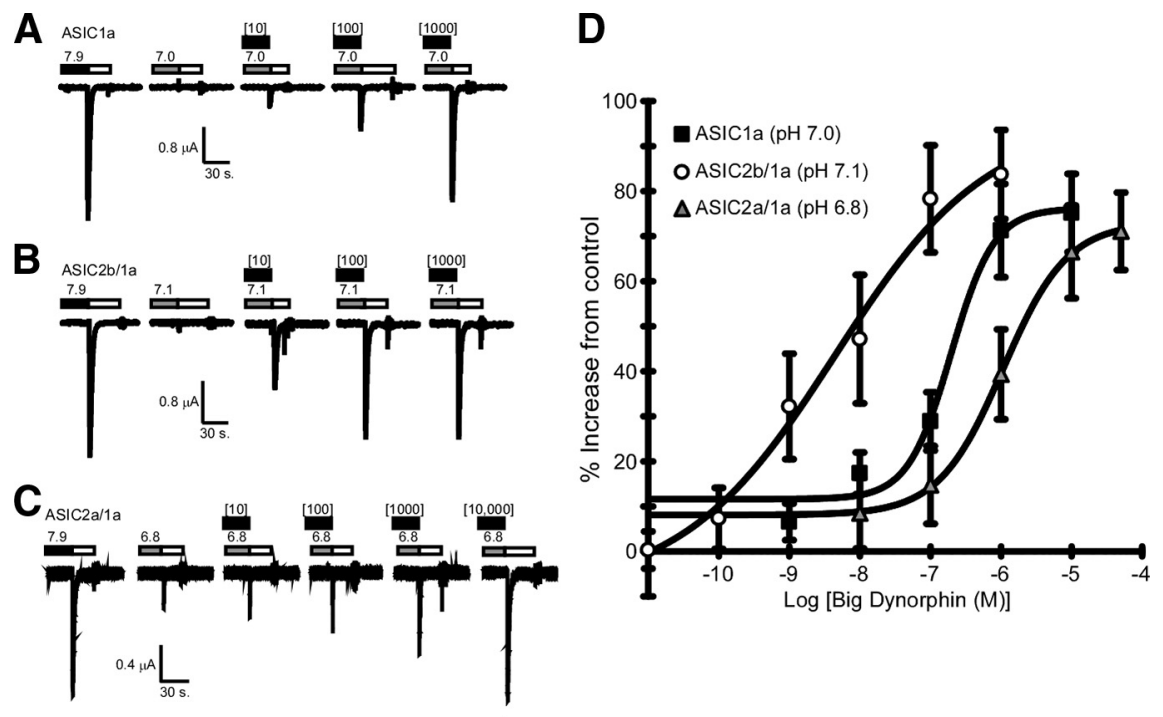

Figure 6. Big Dynorphin prevents steady-state desensitization of ASIC2-containing heteromeric channels. $A-C$, Representative traces of Big Dynorphin effects on steady-state desensitization of acid-evoked current in ASIC1a-expressing (A), ASIC2b/1aexpressing $(\boldsymbol{B})$, and ASIC2a/1a-expressing $(\boldsymbol{C}$ ) oocytes. Control acid-evoked current is shown on the left (white bar, $\mathrm{pH}$ 4.5) from holding pH 7.9 (black bar). Steady-state desensitization was induced by application of the indicated conditioning pH solutions (colored bars) for $2 \mathrm{~min}$ before application of $\mathrm{pH}$ 4.5. Black bars (top) indicate application of peptide for $2 \mathrm{~min}$ before conditioning (pH 7.9; data not shown) and $2 \mathrm{~min}$ at the conditioning pH before acid application. Brackets indicate nanomolar concentrations of Big Dynorphin. D, Quantification of concentration dependence for Big Dynorphin effect on steady-state desensitization. Control current was determined by application of $\mathrm{pH} 4.5$ after conditioning with the indicated $\mathrm{pH}$ solutions in the absence of peptide. Peptide was applied as above at the indicated concentrations. The graph shows increase in pH 4.5-evoked current amplitude in the presence of peptide compared with control conditions. Data was fitted to a Hill equation in individual cells to determine $\mathrm{EC}_{50}$ values. $\mathrm{EC}_{50}=77.45 \pm 45.8 \mathrm{~nm}$ for ASIC1a $(n=7), 3.5 \pm 1.6 \mathrm{~nm}$ for ASIC2b/1a $(n=6)$, and $256.5 \pm 76.2 \mathrm{~nm}$ for ASIC $2 \mathrm{a} / 1 \mathrm{a}(n=4)$. Error bars are the SEM.

ASIC2b/1a heteromeric channels. As we reported previously, Big Dynorphin inhibited steady-state desensitization of ASICla homomeric channels. Concentrations as low as $10 \mathrm{~nm}$ were effective, and the maximal response was observed with $1 \mu \mathrm{M}$ peptide (Fig. $6 A, D)$. Cells expressing ASIC2b/1a showed enhanced sensitivity to Big Dynorphin compared with ASICla alone (Fig. 6B). In fact, $1 \mathrm{~nm}$ Big Dynorphin was sufficient for modulation of ASIC2b/1a current [current was $16.7 \pm$ $4.7 \%$ of maximum for control and $48.8 \pm$ $11.2 \%$ for Big Dynorphin (1 nM); $p=$ $0.04]$, and a maximal effect was observed with 100 nm peptide (Fig. $6 B, D$ ). This effect is specific to the presence of the ASIC2b subunit as ASIC2a/la heteromeric channels required higher concentrations of Big Dynorphin for modulation (Fig. 6C,D).

\section{The ASIC2 gene confers barium sensitivity to proton-gated current in hippocampal neurons}

Our results in a heterologous expression system indicated that ASIC2b/1a channels are both PcTX1 sensitive and inhibited by low millimolar concentration of barium. To determine whether ASIC2b/la contributes to proton-gated currents in neurons, we assessed barium- and PcTX1-mediated inhibition of acid-evoked currents in wild-type (ASIC2 ${ }^{+/+}$) and ASIC2 knockout $\left(\mathrm{ASIC2}^{-1-}\right)$ neurons that lack both ASIC2 subunits (Price et al., 2000). On average, whole-cell proton-gated currents in wild-type neurons were sensitive to both PcTX1 and barium (Fig. $7 A, B$ ). In contrast, proton-gated currents in ASIC2 ${ }^{-1-}$ neurons were inhibited by PcTX1 but not by barium, consistent with a lack of ASIC2b/1a heteromeric channels (Fig. 7A,B). The enhanced PcTX1 inhibition in ASIC2 $2^{-1-}$ neurons compared with wild-type neurons can be explained by a loss of the PcTX1insensitive ASIC2a/1a heteromeric channels as well (Baron et al., 2002a; Jiang et al., 2009). Thus, on average, hippocampal neurons display characteristics suggesting ASIC2b/1a heteromeric channels contribute to proton-gated currents.

We also compared PcTX1 and barium sensitivity in individual neurons. The sensitivity of proton-gated currents to PcTX1 and barium was highly variable between individual wild-type neurons (Fig. $7 C, E$ ). Some neurons showed $\mathrm{pH}$ 6.0-evoked currents robustly inhibited by PcTX1 and little affected by barium, such as ASICla homomeric channels (Fig. 7C). Many neurons displayed $\mathrm{pH}$ 6.0-evoked currents that were robustly inhibited by both PcTX1 and barium, similar to ASIC2b/1a heteromeric channels (Fig. 7C,E). Other neurons showed currents that were predominantly insensitive to both PcTX1 and barium, such as ASIC2a/1a heteromeric channels (Fig. 7C,E). Yet, in the $\mathrm{ASIC2}^{-1-}$ neurons, this variability was abolished, and all neurons showed PcTX1-sensitive, barium-insensitive currents (Fig. $7 E$ ). This is consistent with a prevalence of ASICla homomeric 
channels in ASIC2 ${ }^{-1-}$ neurons. Together, these data suggest that wild-type neurons express a diverse population of ASICs and that ASIC2b/1a channels make a substantial contribution to proton-gated current in cultured neurons.

In an effort to further define the contribution of ASIC2b to proton-gated current in central neurons, we transfected wild-type hippocampal neurons with a shRNA expression plasmid designed to induce RNA interference of ASIC2b mRNA. RT-PCR analysis showed that transfection of neurons with the antiASIC2b shRNA plasmid produced an average reduction of $\mathrm{ASIC} 2 \mathrm{~b}$ mRNA by $31.4 \pm 5.92 \%$ in whole cultures compared with control transfections $(p<0.01)$ (Fig. $8 A$ ). Barium sensitivity, PcTX1 sensitivity, and steady-state desensitization were assessed in individual neurons transfected with the anti-ASIC2b shRNA versus control (Fig. $8 B$ ). We found that sensitivity to these conditions was again highly variable between individual neurons, consistent with the fact that hippocampal neurons express a heterogeneous compliment of ASICs. In both anti-ASIC2b and empty vectortransfected neurons, we recorded cells that were inhibited by PcTX1 and $\mathrm{Zn}^{2+}$ but showed little inhibition with $\mathrm{Ba}^{2+}$ or $\mathrm{pH} 7.4$ conditioning (Fig. 8B, top). Other cells showed considerable inhibition with $\mathrm{pH} 7.4$ conditioning, $\mathrm{Ba}^{2+}$, and PcTX1 (Fig. $8 B$, middle). Others, still, were not affected by pH 7.4 conditioning, $\mathrm{Ba}^{2+}$, or PcTX1 (Fig. $8 B$, bottom). Together, these data suggest individual neurons have proton-gated current profiles matching ASIC1a homomeric channels, ASIC2b/la heteromers, and ASIC2a/1a heteromers, respectively. However, we found a significant reduction of the inhibitory effects of $\mathrm{pH}$ 7.4-condtioning and barium treatments in antiASIC2b shRNA-transfected cells compared with control cells (Fig. $8 C$ ). Based on these data, we calculated the relative percentage of neurons expressing predominantly ASICla-like homomers ( $>20 \%$ PcTX1 inhibition, $<20 \% \mathrm{Ba}^{2+}$ inhibition), ASIC2b/1a-like heteromers ( $>20 \%$ PcTX1 inhibition, $>20 \mathrm{Ba}^{2+}$ inhibition), and ASIC2a/1a-like heteromers ( $<20 \%$ PcTX1 inhibition, $<20 \% \mathrm{Ba}^{2+}$ inhibition) (Fig. $8 D$ ). We found that in control neurons, $45 \%$ of cells predominantly displayed ASIC2b/1a-like profiles, and this number was reduced to $10 \%$ in anti-ASIC2b shRNA plasmid-transfected cells (Fig. 8D). Together, these data demonstrate a considerable presence of ASIC2b/1a heteromeric channels in central neurons.

\section{The ASIC2 gene is required for barium-mediated protection from acidosis}

Prolonged acidosis induces toxicity in central neurons in an ASICla-dependent manner, and treatment with PcTX1 prevents ASIC1a-dependent neuronal death (Xiong et al., 2004; Gao et al., 2005; Sherwood and Askwith, 2009). ASIC-mediated neuronal death is thought to be linked to activity of the calcium-permeable ASIC1a homomeric channels. Since our data indicate that

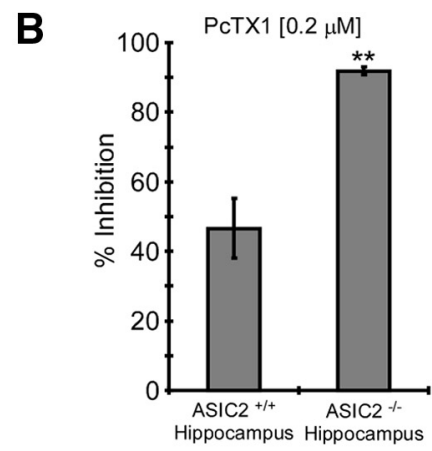

\section{ASIC2 ${ }^{+/+}$Hippocampus}

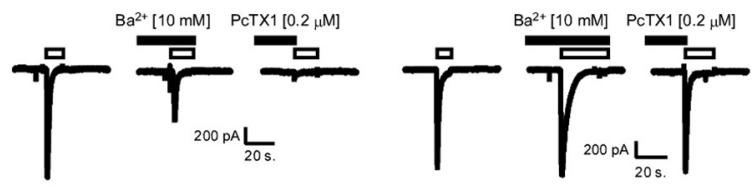

$\mathbf{E}$

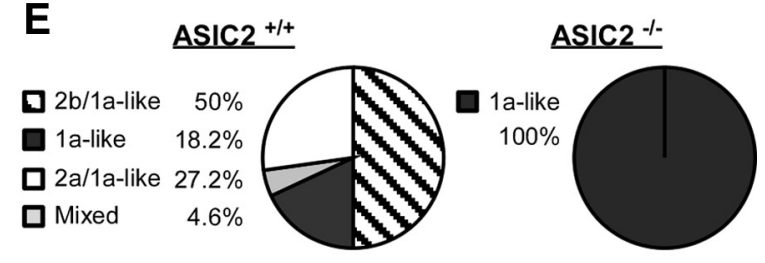

Figure 7. $\quad$ ASIC2 is required for dynamic barium sensitivity in hippocampal neurons. $\boldsymbol{A}, \boldsymbol{B}$, Quantification of Ba ${ }^{2+}(\boldsymbol{A})$ and PCTX1 $(\boldsymbol{B})$ inhibition in wild-type and ASIC2 knock-out neurons. The whole-cell patch-clamp technique was used to record pH 6.0-evoked (n) was 7.9) in day 14-21 cultured hippocampal neurons. Current was evoked in the presence of $10 \mathrm{~mm} \mathrm{Ba}^{2+}$ or , and $n=14$ for ASIC2 ${ }^{-1-}$. $^{* *} p<0.01$, compared with ASIC2 ${ }^{+/+}$group with $t$ test analysis (2-tailed, unpaired data) C, Representative traces showing dynamic sensitivity of acid-evoked current to extracellular Ba ${ }^{2+}$ and PcTX1 in individual neurons. bars indicate perfusion of extracellular solution containing $10 \mathrm{~mm} \mathrm{Ba}^{2+}$ before and during acid application or perfusion of inhibition in hippocampal neurons lacking the ASIC2 gene (ACCN1). The effects of $\mathrm{Ba}^{2+}$ and PCTX1 on acid-evoked current were $0.2 \mu \mathrm{M}$ PcTX1. The graph shows the relative percentage of individual cells within each group that displayed the indicated phenoinhibition; ASIC2a/1a, $<20 \% \mathrm{Ba}^{2+}$ inhibition, $<20 \%$ PcTX1 inhibition; mixed, $>20 \% \mathrm{Ba}^{2+}$ inhibition, $<20 \%$ PcTX1 inhibition. $n=22$ for $\mathrm{ASIC}^{+/+}$, and $n=14$ for ASIC2 ${ }^{-1-}$. Error bars are the SEM.

ASIC2b/1a channels are also calcium permeable, we reasoned that ASIC2b/1a channels may also contribute to acid-induced neuronal death. Therefore, we assessed whether the presence of $10 \mathrm{~mm}$ barium affects acidosis-induced cortical neuron death (Fig. 9A). Barium inhibits a variety of potassium channels and thus can alter intrinsic excitability of neurons and affect excitotoxic death. However, these experiments were performed in the presence of excitotoxicity inhibitors to specifically isolate acidosis and ASIC-mediated pathways. In wild-type neurons, acidosis caused significant cellular damage as indicated by MTT cleavage (acid treatment was $34.2 \pm 9.5 \%$ reduced MTT cleavage vs control; $n=7$ ) (Fig. 9B). In the presence of barium, the effect of acidosis on wild-type neurons was robustly reduced (acid treatment plus barium was $3.6 \pm 6.4 \%$ increased MTT cleavage vs barium control; $n=7 ; p=0.006$ ) (Fig. 9B). This assay was also performed on neurons lacking ASIC2 subunits (ASIC2 ${ }^{-1-}$ ). In the absence of barium, ASIC2 knock-out neurons showed an amount of damage after prolonged acidosis that was similar to wild-type neurons (acid treatment was $43.0 \pm 7.0 \%$ reduced MTT cleavage vs control; $n=7$ ) (Fig. 9B). However, barium failed to prevent acidosis effects in ASIC2 ${ }^{-/-}$neurons (acid 


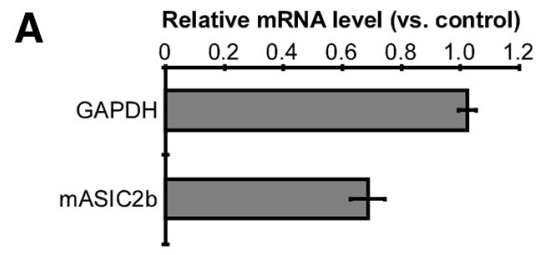

B
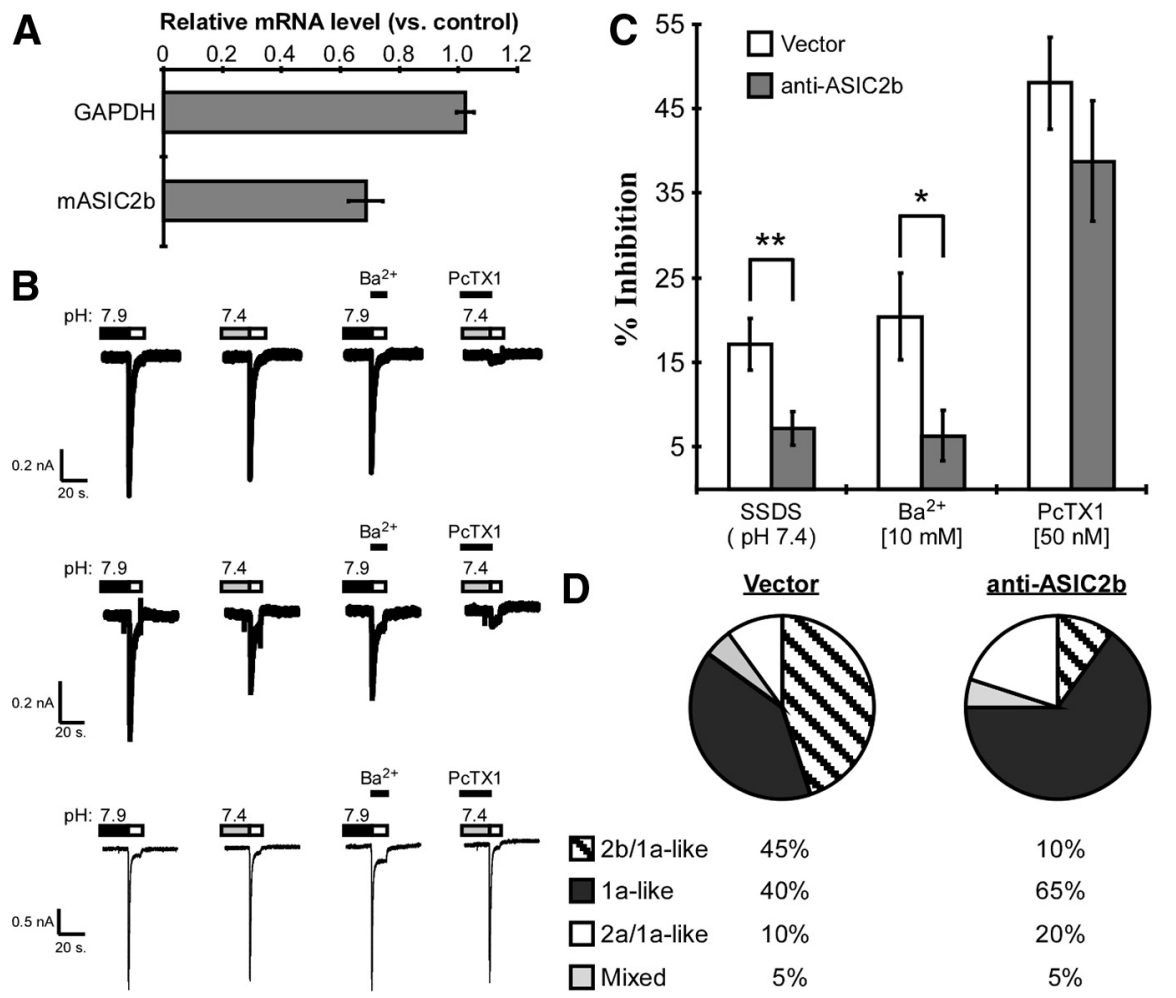
$45 \%$
$40 \%$
$10 \%$
$5 \%$

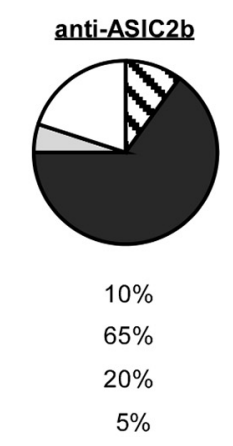

Figure 8. Knockdown of ASIC2b alters barium sensitivity and steady-state desensitization of hippocampal proton-gated currents. A, Quantification of anti-ASIC2b shRNA effects on genomic mRNA. The graph indicates the fold change in specified mRNAs between anti-ASIC2b shRNA vector-transfected cultures and empty vector-transfected cultures, as measured by quantitative RT-PCR (see Materials and Methods). ${ }^{* *} p<0.01$ ( $t$ test, unpaired); $n=3$. $\boldsymbol{B}$, Three representative traces showing dynamic sensitivity of acid-evoked current to pH 7.4 preconditioning, extracellular $\mathrm{Ba}^{2+}$, and PcTX1 in wild-type hippocampal neurons transfected with empty vector. Maximal current (left) was considered current evoked by perfusion of pH 6.0 (white bars) from a holding pH of 7.9 in the absence of $\mathrm{Ba}^{2+}$ and PCTX1. Colored bars indicate holding pH before acid application (white bars). Black bars (above trace) indicate perfusion of acidic solution containing either $10 \mathrm{~mm} \mathrm{Ba}{ }^{2+}$ or perfusion of $\mathrm{pH} 7.4$ solutions containing 50 nм PCTX1 for 1.5 min before acid application as indicated. C, Comparison of pH 7.4 preconditioning, $\mathrm{Ba}^{2+}$ and PcTX1 effects on acid-evoked current amplitude in vector-transfected cells and anti-ASIC2b shRNA-transfected cells. Average current amplitude after the specified treatments was normalized to maximal current amplitude, and the percentage inhibition is the difference in normalized current amplitude. ${ }^{*} p<0.05 ;{ }^{* *} p<0.01$ ( $t$ test, unpaired); $n=20 . D$, ASIC population analysis in empty vector- or anti-ASIC2b shRNA-transfected neurons. Individual neurons were classified as having a type ASIC1a, ASIC2b/1a, or ASIC2a/1a phenotype based on their response to extracellular $\mathrm{Ba}^{2+}$ and PCTX1 as before; $n=20$ for both groups. Error bars are the SEM.

treatment plus barium was $30.2 \pm 8.1 \%$ reduced MTT cleavage vs barium control; $n=7 ; p=0.25$ ), suggesting that bariummediated neuroprotection from acidosis required the presence of ASIC2 subunits. Because only the ASIC2b subunit conferred significant barium sensitivity, these results suggest the bariumdependent protection observed in wild-type cells is mediated by ASIC2b/1a heteromers. Together, these results indicate that in wild-type neurons, ASIC2 subunits contribute to acidosisinduced neuronal death and pharmacological blockers of ASIC2b/1a heteromeric channels can limit acidosis-induced toxicity.

\section{Discussion}

ASIC2b mRNA is abundant in neurons of the CNS in a pattern that overlaps with ASIC1a and the other ASIC2 transcript variant, ASIC2a (Price et al., 1996; Lingueglia et al., 1997). Identifying a function for ASIC2b in central neurons has been complicated by the fact that (1) ASIC2b fails to produce proton-gated currents when expressed alone, (2) ASIC2b/2a heteromeric channels require extremely acidic $\mathrm{pHs}$ for activation (below $\mathrm{pH} 4.0$ ) that likely do not occur in the CNS (Ugawa et al., 2003), and (3) unique properties of ASIC2b/1a heteromeric channels and their existence in CNS neurons were unclear. Here, we provide the first detailed description of the unique properties of ASIC2b/1a heteromeric channels. We find that ASIC2b/1a channels are indistinguishable from ASIC1a homomeric channels in apparent proton sensitivity of activation and inactivation kinetics. Like ASIC1a homomeric channels, they are also PcTX1 sensitive and calcium permeable. Yet, ASIC2b/1a channels differ from ASIC1a homomeric channels in that they are sensitive to barium and TEA, undergo steady-state desensitization at more basic $\mathrm{pH}$ values ( $\mathrm{pH}$ 7.4), and are modulated by lower concentrations of Big Dynorphin. It should be noted that dynorphin modulation was measured at different $\mathrm{pH}$ values for each channel subtype because each channel displays intrinsic differences in the $\mathrm{pH}$ dependence of steady-state desensitization. Thus, changes in apparent Big Dynorphin affinity could be caused by ASIC subunit-dependent changes in dynorphin affinity or could be the result of a $\mathrm{pH}$ dependence for Big Dynorphin action. In other heteromeric ASIC combinations, such as $\mathrm{ASIC} 2 \mathrm{~b} / 2 \mathrm{a}$ and ASIC2b/3, ASIC2b enhances acid-induced sustained current (Ugawa et al., 2003; Deval et al., 2004). Notably, this property was not different between ASIC2b/1a heteromers and ASIC1a homomeric channels. The fact that ASIC2b confers distinct properties to different heteromeric channels suggests that the specific contribution of ASIC $2 b$ is dependent on the identity of the other subunit present within the heteromeric channel.

Heteromultimeric channels composed of ASIC1a and ASIC2a differ from ASIC1a homomeric channels by requiring more acidic $\mathrm{pHs}$ for activation and steady-state desensitization as well as inactivating at a distinctly different rate (Bassilana et al., 1997; Benson et al., 1999; Baron et al., 2002a; Askwith et al., 2004; Hesselager et al., 2004). In addition, ASIC2a/la heteromeric channels are insensitive to PcTX1, require greater concentrations of Big Dynorphin for modulation, and are potentiated by extracellular zinc (Escoubas et al., 2000; Chen et al., 2005, 2006; Sherwood and Askwith, 2009). Thus, ASIC2a alters the kinetics of ASIC1a channels in a manner distinct from ASIC2b. In fact, for properties such as steady-state desensitization, dynorphin sensitivity, low-affinity zinc modulation, and PcTX1 inhibition, ASIC2a and ASIC2b have opposite effects. However, some properties conferred by ASIC2 subunits are similar. TEA inhibited both ASIC2a/1a and ASIC2b/1a heteromeric channels equally and had little effect on ASICla homomeric channels. Inhibition by barium was significantly more pronounced with ASIC2b/1a heteromeric channels compared with ASIC2a/1a heteromeric channels. The difference in the role of ASIC2b relative to ASIC2a must result from a difference in their amino acid sequences. ASIC2b and ASIC2a differ in the first 237 (ASIC2b) and 186 (ASIC2a) amino acids of the protein (Lingueglia et al., 1997). The 
A
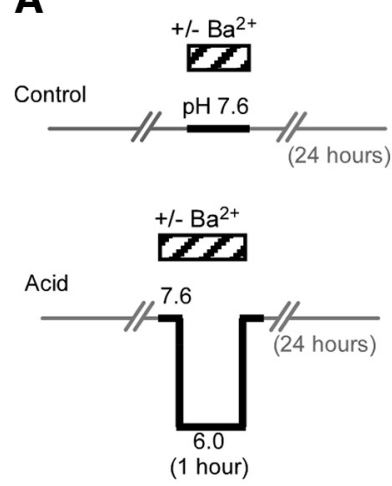

B

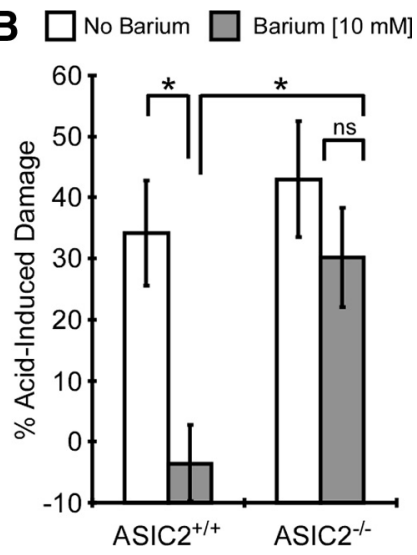

Figure 9. ASIC2 is required for barium inhibition of acid-induced neuronal damage. $A$, Schematic of the conditions tested in cortical neuron damage assay. The horizontal axis represents time, and the vertical axis represents pH. Gray lines indicate time in tissue culture medium. Black lines indicate time in artificial extracellular solution during intervention. Interventions were done in the presence or absence of $10 \mathrm{~mm} \mathrm{Ba}^{2+}$ (striped bars). Note that all experiments were done in the presence of excitotoxicity inhibitors (see Materials and Methods). $\boldsymbol{B}$, Quantification of acid-induced damage in wild-type and ASIC 2 knock-out neurons after acidosis interventions. Metabolic activity of neurons was assessed $24 \mathrm{~h}$ after acidosis interventions using an MTT assay kit (see Materials and Methods). \% Acid-Induced Damage, Percentage decrease in MTT cleavage in the Acid groups compared with the No Acid groups. Note that the result of ASIC2 ${ }^{+/+}$neurons exposed to acidosis in the presence of barium are not significantly different from control or $0 \%$ acid-induced damage. ${ }^{*} p<0.05$, ANOVA (1-way). $n=7$ different cultures for $\mathrm{ASIC}^{+/+}$, and $n=7$ different cultures for $\mathrm{ASIC}^{-1-}$. Error bars are the SEM.

differential region includes the intracellular $\mathrm{N}$ terminus, transmembrane domain 1 (TM1), and part of the extracellular domain, some of which appears to contribute to the extracellular vestibule of the pore (Jasti et al., 2007; Gonzales et al., 2009). Our data suggest that TEA and barium block the pore of ASIC2b/1a channels in a mechanism similar to inhibition of voltage-gated potassium channels (Heginbotham and MacKinnon, 1992; Hurst et al., 1995; Harris et al., 1998). Thus, it is tempting to speculate that amino acids near transmembrane domain 2 (that are conserved between ASIC2a and ASIC2b) may determine TEA block, but substantial barium inhibition requires the TM1 domain of ASIC2b. Additionally, residues $\mathrm{N}$ terminal to TM1 (that are distinct between ASIC2a and ASIC2b) have also been shown to affect ASIC ion permeability and could also affect calcium permeability as well as TEA or barium pore block (Coscoy et al., 1999).

Our results indicate that ASIC2b/1a heteromeric channels contribute to endogenous proton-gated currents in cultured neurons. On average, whole-cell proton-gated current in hippocampal neurons was inhibited by barium, and a relatively large percentage of individual neurons showed proton-gated currents that were both PcTX1 and barium sensitive (consistent with ASIC2b/1a). Furthermore, barium inhibition was eliminated in the ASIC2 knock-out, which lacks ASIC2b, and significantly reduced in neurons transfected with anti-ASIC2b shRNA plasmids. Thus, central neurons possess proton-gated currents consistent with three ASIC subtypes: ASIC2b/la heteromeric channels, ASIC2a/1a heteromeric channels, and ASIC1a homomeric channels. Many processes in vivo and in vitro are attributed to homomeric ASIC1a channels because of their unique sensitivity to PcTX1 (Escoubas et al., 2000; Chen et al., 2005, 2006). We show, for the first time, that heteromeric ASIC2b/1a channels are also inhibited by PcTX1. This suggests ASIC2b/la could contribute to processes previously thought to be specific to ASICla, such as

fear-related learning and memory, unconditioned fear behavior, pain processing and neuronal damage after stroke (Xiong et al., 2004; Dwyer et al., 2009; Gregoire and Matricon, 2009; Xu and Duan, 2009; Ziemann et al., 2009). Yet, a specific role for ASIC2 subunits in behavior and central neuronal damage has not been reported. We speculate that ASIC2b might provide a unique contribution to ASICla-dependent currents by facilitating interactions with other proteins. ASIC2b binds PICK-1 through a C-terminal PDZ domain and mediates PKC regulation of the peripherally expressed ASIC subunit ASIC3 (Deval et al., 2004). Although ASIC1a and ASIC2a can also bind PICK-1, the presence of ASIC2b could offer a unique contribution to PICK-1 or PKC action in the heteromeric channel (Baron et al., 2002b; Duggan et al., 2002; Hruska-Hageman et al., 2002). Additionally, the unique intracellular $\mathrm{N}$ terminus of ASIC2b contains potential phosphorylation sites that could play a role in channel regulation. Finally, ASIC2b could play a role in ASIC1a localization. ASIC1a subunits are expressed on the cell body, dendrites, and dendritic spines of neurons (Wemmie et al., 2003). Synaptically localized ASIC1a affects dendritic spine density, and the C-terminal PDZ proteinbinding motif of ASIC2a facilitates ASIC1a localization to dendritic spines via an interaction with PSD-95 (Zha et al., 2006, 2009). It is possible that ASIC2b similarly mediates localization of ASIC2b/1a heteromeric channels to dendritic spines as ASIC2b would possess the same PDZ protein-binding motif. However, unlike ASIC2a/1a heteromers, ASIC2b/1a channels are calcium permeable like ASIC1a homomeric channels. Thus, ASIC2b potentially offers a mechanism to regulate ASICla activity without diminishing downstream calcium-dependent signaling events, including those associated with dendritic spine density and neuronal death (Xiong et al., 2006; Zha et al., 2006).

Our data suggest that ASIC2 subunits (ASIC2b, in particular) directly contribute to acidosis-induced neuronal death. We find that barium has a strong effect on acidosis-induced neuronal death in wild-type neurons (and not ASIC2 knock-out neurons), suggesting that activation of ASIC2b/la heteromeric channels mediates neuronal death. The fact that barium so profoundly inhibited acid-induced neuronal death was surprising given that barium-resistant ASIC1a homomeric channels, which are known to mediate acid-induced death, are also present in these neurons (Duan et al., 2011). It is possible that our results reflect an inherent difference in sensitivity to acid of neurons that predominantly express ASIC2b/1a heteromeric channels versus ASIC1a homomeric channels. In support of this idea, certain hippocampal neuron populations are selectively vulnerable to seizure-induced damage compared with others, which may be linked to specific ASIC subtypes expressed (Weng et al. 2010). We were also surprised to find no inherent difference in acidosis-induced neuronal death between wild-type and ASIC2 ${ }^{-1-}$ neurons. This could be attributable to a combined effect of losing both ASIC2a and ASIC2b, which have opposing effects on the characteristics of proton-gated currents. Indeed, previous reports have speculated that the presence of ASIC2 (specifically ASIC2a) attenuates acidosis-induced neuronal death (Yermolaieva et al., 2004; Chu et al., 2006). In addition, ASIC2 has been shown to be protective in mouse models of light-induced retinal degeneration (Ettaiche et al., 2004). However, other studies have suggested that the ASIC2 gene contributes to damage (Peng et al., 2004). Our results are the first to directly show ASIC2 contributes to acidosisinduced neuronal death. This may be important for other neurological disorders. Single nucleotide polymorphisms in the ACCN1 (ASIC2) gene may contribute to multiple sclerosis in humans, a condition that may also involve ASICla-mediated 
neuronal death (Bernardinelli et al., 2007; Friese et al., 2007; Vergo et al., 2011). The fact that the ASIC2b/1a channels are inhibited by compounds that do not affect ASICla homomeric channels indicates that ASIC2b/1a channels can be specifically targeted for therapeutic advantage. As specific ASIC subtypes appear to dominate proton-gated currents in subpopulations of neurons (Weng et al., 2010), such therapeutic compounds could provide effective inhibition of acidosis-induced neuronal death in populations of neurons that would otherwise be unaffected by ASIC1a homomer-specific channel inhibitors.

\section{References}

Adams CM, Price MP, Snyder PM, Welsh MJ (1999) Tetraethylammonium block of the BNC1 channel. Biophys J 76:1377-1383.

Arias RL, Sung ML, Vasylyev D, Zhang MY, Albinson K, Kubek K, Kagan N, Beyer C, Lin Q, Dwyer JM, Zaleska MM, Bowlby MR, Dunlop J, Monaghan M (2008) Amiloride is neuroprotective in an MPTP model of Parkinson's disease. Neurobiol Dis 31:334-341.

Askwith CC, Wemmie JA, Price MP, Rokhlina T, Welsh MJ (2004) Acidsensing ion channel 2 (ASIC2) modulates ASIC1 $\mathrm{H}+$-activated currents in hippocampal neurons. J Biol Chem 279:18296-18305.

Babini E, Paukert M, Geisler HS, Grunder S (2002) Alternative splicing and interaction with di- and polyvalent cations control the dynamic range of acid-sensing ion channel 1 (ASIC1). J Biol Chem 277:41597-41603.

Baron A, Schaefer L, Lingueglia E, Champigny G, Lazdunski M (2001) $\mathrm{Zn} 2+$ and $\mathrm{H}+$ are coactivators of acid-sensing ion channels. J Biol Chem 276:35361-35367.

Baron A, Waldmann R, Lazdunski M (2002a) ASIC-like, proton-activated currents in rat hippocampal neurons. J Physiol 539:485-494.

Baron A, Deval E, Salinas M, Lingueglia E, Voilley N, Lazdunski M (2002b) Protein kinase $\mathrm{C}$ stimulates the acid-sensing ion channel ASIC2a via the PDZ domain-containing protein PICK1. J Biol Chem 277:50463-50468.

Bassilana F, Champigny G, Waldmann R, de Weille JR, Heurteaux C, Lazdunski M (1997) The acid-sensitive ionic channel subunit ASIC and the mammalian degenerin MDEG form a heteromultimeric $\mathrm{H}+$-gated $\mathrm{Na}+$ channel with novel properties. J Biol Chem 272:28819-28822.

Bassler EL, Ngo-Anh TJ, Geisler HS, Ruppersberg JP, Grunder S (2001) Molecular and functional characterization of acid-sensing ion channel (ASIC) 1b. J Biol Chem 276:33782-33787.

Benson CJ, Eckert SP, McCleskey EW (1999) Acid-evoked currents in cardiac sensory neurons: a possible mediator of myocardial ischemic sensation. Circ Res 84:921-928.

Bernardinelli L, Murgia SB, Bitti PP, Foco L, Ferrai R, Musu L, Prokopenko I, Pastorino R, Saddi V, Ticca A, Piras ML, Cox DR, Berzuini C (2007) Association between the ACCN1 gene and multiple sclerosis in Central East Sardinia. PLoS One 2:e480.

Chen X, Kalbacher H, Grunder S (2005) The tarantula toxin psalmotoxin 1 inhibits acid-sensing ion channel (ASIC) 1a by increasing its apparent H+ affinity. J Gen Physiol 126:71-79.

Chen X, Kalbacher H, Grunder S (2006) Interaction of acid-sensing ion channel (ASIC) 1 with the tarantula toxin psalmotoxin 1 is state dependent. J Gen Physiol 127:267-276.

Chu XP, Wemmie JA, Wang WZ, Zhu XM, Saugstad JA, Price MP, Simon RP, Xiong ZG (2004) Subunit-dependent high-affinity zinc inhibition of acid-sensing ion channels. J Neurosci 24:8678-8689.

Chu XP, Close N, Saugstad JA, Xiong ZG (2006) ASIC1a-specific modulation of acid-sensing ion channels in mouse cortical neurons by redox reagents. J Neurosci 26:5329-5339.

Coryell MW, Wunsch AM, Haenfler JM, Allen JE, McBride JL, Davidson BL, Wemmie JA (2008) Restoring acid-sensing ion channel-1a in the amygdala of knock-out mice rescues fear memory but not unconditioned fear responses. J Neurosci 28:13738-13741.

Coryell MW, Wunsch AM, Haenfler JM, Allen JE, Schnizler M, Ziemann AE, Cook MN, Dunning JP, Price MP, Rainier JD, Liu Z, Light AR, Langbehn DR, Wemmie JA (2009) Acid-sensing ion channel-1a in the amygdala, a novel therapeutic target in depression-related behavior. J Neurosci 29:5381-5388.

Coscoy S, de Weille JR, Lingueglia E, Lazdunski M (1999) The pretransmembrane 1 domain of acid-sensing ion channels participates in the ion pore. J Biol Chem 274:10129-10132.

Deval E, Salinas M, Baron A, Lingueglia E, Lazdunski M (2004) ASIC2b- dependent regulation of ASIC3, an essential acid-sensing ion channel subunit in sensory neurons via the partner protein PICK-1. J Biol Chem 279:19531-19539.

Duan B, Wang YZ, Yang T, Chu XP, Yu Y, Huang Y, Cao H, Hansen J, Simon RP, Zhu MX, Xiong ZG, Xu TL (2011) Extracellular spermine exacerbates ischemic neuronal injury through sensitization of ASICla channels to extracellular acidosis. J Neurosci 31:2101-2112.

Duggan A, Garcia-Anoveros J, Corey DP (2002) The PDZ domain protein PICK1 and the sodium channel $\mathrm{BNaCl}$ interact and localize at mechanosensory terminals of dorsal root ganglion neurons and dendrites of central neurons. J Biol Chem 277:5203-5208.

Dwyer JM, Rizzo SJ, Neal SJ, Lin Q, Jow F, Arias RL, Rosenzweig-Lipson S, Dunlop J, Beyer CE (2009) Acid sensing ion channel (ASIC) inhibitors exhibit anxiolytic-like activity in preclinical pharmacological models. Psychopharmacology (Berl) 203:41-52.

Eaton DC, Brodwick MS (1980) Effects of barium on the potassium conductance of squid axon. J. Gen Physiol 75:727-750.

Escoubas P, De Weille JR, Lecoq A, Diochot S, Waldmann R, Champigny G, Moinier D, Menez A, Lazdunski M (2000) Isolation of a tarantula toxin specific for a class of proton-gated $\mathrm{Na}+$ channels. J Biol Chem 275:25116-25121.

Escoubas P, Bernard C, Lambeau G, Lazdunski M, Darbon H (2003) Recombinant production and solution structure of $\mathrm{PcTx} 1$, the specific peptide inhibitor of ASICla proton-gated cation channels. Protein Sci 12:1332-1343.

Ettaiche M, Guy N, Hofman P, Lazdunski M, Waldmann R (2004) Acidsensing ion channel 2 is important for retinal function and protects against light-induced retinal degeneration. J Neurosci 24:1005-1012.

Friese MA, Craner MJ, Etzensperger R, Vergo S, Wemmie JA, Welsh MJ, Vincent A, Fugger L (2007) Acid-sensing ion channel-1 contributes to axonal degeneration in autoimmune inflammation of the central nervous system. Nat Med 13:1483-1489.

Gao J, Wu LJ, Xu L, Xu TL (2004) Properties of the proton-evoked currents and their modulation by $\mathrm{Ca} 2+$ and $\mathrm{Zn} 2+$ in the acutely dissociated hippocampus CA1 neurons. Brain Res 1017:197-207.

Gao J, Duan B, Wang DG, Deng XH, Zhang GY, Xu L, Xu TL (2005) Coupling between NMDA receptor and acid-sensing ion channel contributes to ischemic neuronal death. Neuron 48:635-646.

Gonzales EB, Kawate T, Gouaux E (2009) Pore architecture and ion sites in acid-sensing ion channels and P2X receptors. Nature 460:599-604.

Gregoire S, Matricon J (2009) Differential involvement of ASIC1a in the basolateral amygdala in fear memory and unconditioned fear responses. J Neurosci 29:6053-6054.

Harris RE, Larsson HP, Isacoff EY (1998) A permanent ion binding site located between two gates of the Shaker $\mathrm{K}+$ channel. Biophys J 74:1808-1820.

Heginbotham L, MacKinnon R (1992) The aromatic binding site for tetraethylammonium ion on potassium channels. Neuron 8:483-491.

Hesselager M, Timmermann DB, Ahring PK (2004) pH dependency and desensitization kinetics of heterologously expressed combinations of acid-sensing ion channel subunits. J Biol Chem 279:11006-11015.

Hoagland EN, Sherwood TW, Lee KG, Walker CJ, Askwith CC (2010) Identification of a calcium permeable human acid-sensing ion channel 1 transcript variant. J Biol Chem 285:41852-41862.

Hruska-Hageman AM, Wemmie JA, Price MP, Welsh MJ (2002) Interaction of the synaptic protein PICK1 (protein interacting with C kinase 1) with the non-voltage gated sodium channels $\mathrm{BNCl}$ (brain $\mathrm{Na}+$ channel 1) and ASIC (acid-sensing ion channel). Biochem J 361:443-450.

Hurst RS, Latorre R, Toro L, Stefani E (1995) External barium block of Shaker potassium channels: evidence for two binding sites. J Gen Physiol 106:1069-1087.

Jasti J, Furukawa H, Gonzales EB, Gouaux E (2007) Structure of acidsensing ion channel 1 at 1.9 A resolution and low pH. Nature 449:316-323.

Jiang Q, Li MH, Papasian CJ, Branigan D, Xiong ZG, Wang JQ, Chu XP (2009) Characterization of acid-sensing ion channels in medium spiny neurons of mouse striatum. Neuroscience 162:55-66.

Jiang Y, MacKinnon R (2000) The barium site in a potassium channel by X-ray crystallography. J Gen Physiol 115:269-272.

Lingueglia E, de Weille JR, Bassilana F, Heurteaux C, Sakai H, Waldmann R, Lazdunski M (1997) A modulatory subunit of acid sensing ion channels in brain and dorsal root ganglion cells. J Biol Chem 272:29778-29783. 
Mazzuca M, Heurteaux C, Alloui A, Diochot S, Baron A, Voilley N, Blondeau N, Escoubas P, Gelot A, Cupo A, Zimmer A, Zimmer AM, Eschalier A, Lazdunski M (2007) A tarantula peptide against pain via ASICla channels and opioid mechanisms. Nat Neurosci 10:943-945.

Peng BG, Ahmad S, Chen S, Chen P, Price MP, Lin X (2004) Acid-sensing ion channel 2 contributes a major component to acid-evoked excitatory responses in spiral ganglion neurons and plays a role in noise susceptibility of mice. J Neurosci 24:10167-10175.

Pignataro G, Simon RP, Xiong ZG (2007) Prolonged activation of ASICla and the time window for neuroprotection in cerebral ischaemia. Brain 130:151-158.

Price MP, Snyder PM, Welsh MJ (1996) Cloning and expression of a novel human brain $\mathrm{Na}+$ channel. J Biol Chem 271:7879-7882.

Price MP, Lewin GR, McIlwrath SL, Cheng C, Xie J, Heppenstall PA, Stucky CL, Mannsfeldt AG, Brennan TJ, Drummond HA, Qiao J, Benson CJ, Tarr DE, Hrstka RF, Yang B, Williamson RA, Welsh MJ (2000) The mammalian sodium channel BNC1 is required for normal touch sensation. Nature 407:1007-1011.

Salinas M, Rash LD, Baron A, Lambeau G, Escoubas P, Lazdunski M (2006) The receptor site of the spider toxin PcTx1 on the proton-gated cation channel ASIC1a. J Physiol 570:339-354.

Sherwood TW, Askwith CC (2009) Dynorphin opioid peptides enhance acid-sensing ion channel la activity and acidosis-induced neuronal death. J Neurosci 29:14371-14380.

Taglialatela M, Vandongen AM, Drewe JA, Joho RH, Brown AM, Kirsch GE (1991) Patterns of internal and external tetraethylammonium block in four homologous K+ channels. Mol Pharmacol 40:299-307.

Ugawa S, Yamamoto T, Ueda T, Ishida Y, Inagaki A, Nishigaki M, Shimada S (2003) Amiloride-insensitive currents of the acid-sensing ion channel-2a (ASIC2a)/ASIC2b heteromeric sour-taste receptor channel. J Neurosci 23:3616-3622.

Vergo S, Craner MJ, Etzensperger R, Attfield K, Friese MA, Newcombe J, Esiri M, Fugger L (2011) Acid-sensing ion channel 1 is involved in both axonal injury and demyelination in multiple sclerosis and its animal model. Brain 134:571-584.

Voilley N (2004) Acid-sensing ion channels (ASICs): new targets for the analgesic effects of non-steroid anti-inflammatory drugs (NSAIDs). Curr Drug Targets Inflamm Allergy 3:71-79.

Waldmann R (2001) Proton-gated cation channels—neuronal acid sensors in the central and peripheral nervous system. Adv Exp Med Biol 502:293-304.

Waldmann R, Lazdunski M (1998) H(+)-gated cation channels: neuronal acid sensors in the NaC/DEG family of ion channels. Curr Opin Neurobiol 8:418-424.

Waldmann R, Champigny G, Bassilana F, Heurteaux C, Lazdunski M (1997) A proton-gated cation channel involved in acid-sensing. Nature 386:173-177.

Wemmie JA, Chen J, Askwith CC, Hruska-Hageman AM, Price MP, Nolan BC, Yoder PG, Lamani E, Hoshi T, Freeman JH Jr, Welsh MJ (2002) The acid-activated ion channel ASIC contributes to synaptic plasticity, learning, and memory. Neuron 34:463-477.

Wemmie JA, Askwith CC, Lamani E, Cassell MD, Freeman JH Jr, Welsh MJ (2003) Acid-sensing ion channel 1 is localized in brain regions with high synaptic density and contributes to fear conditioning. J Neurosci 23:5496-5502.

Wemmie JA, Price MP, Welsh MJ (2006) Acid-sensing ion channels: advances, questions and therapeutic opportunities. Trends Neurosci 29:578-586.

Weng JY, Lin YC, Lien CC (2010) Cell type-specific expression of acidsensing ion channels in hippocampal interneurons. J Neurosci 30:6548-6558

Wong HK, Bauer PO, Kurosawa M, Goswami A, Washizu C, Machida Y, Tosaki A, Yamada M, Knopfel T, Nakamura T, Nukina N (2008) Blocking acid-sensing ion channel 1 alleviates Huntington's disease pathology via an ubiquitin-proteasome system-dependent mechanism. Hum Mol Genet 17:3223-3235.

Wu LJ, Duan B, Mei YD, Gao J, Chen JG, Zhuo M, Xu L, Wu M, Xu TL (2004) Characterization of acid-sensing ion channels in dorsal horn neurons of rat spinal cord. J Biol Chem 279:43716-43724.

Xiong ZG, Zhu XM, Chu XP, Minami M, Hey J, Wei WL, MacDonald JF, Wemmie JA, Price MP, Welsh MJ, Simon RP (2004) Neuroprotection in ischemia: blocking calcium-permeable acid-sensing ion channels. Cell 118:687-698.

Xiong ZG, Chu XP, Simon RP (2006) Ca2+ -permeable acid-sensing ion channels and ischemic brain injury. J Membr Biol 209:59-68.

Xiong ZG, Pignataro G, Li M, Chang SY, Simon RP (2008) Acid-sensing ion channels (ASICs) as pharmacological targets for neurodegenerative diseases. Curr Opin Pharmacol 8:25-32.

Xu TL, Duan B (2009) Calcium-permeable acid-sensing ion channel in nociceptive plasticity: a new target for pain control. Prog Neurobiol 87:171-180.

Yermolaieva O, Leonard AS, Schnizler MK, Abboud FM, Welsh MJ (2004) Extracellular acidosis increases neuronal cell calcium by activating acidsensing ion channel 1a. Proc Natl Acad Sci U S A 101:6752-6757.

Zha XM, Wemmie JA, Green SH, Welsh MJ (2006) Acid-sensing ion channel 1a is a postsynaptic proton receptor that affects the density of dendritic spines. Proc Natl Acad Sci U S A 103:16556-16561.

Zha XM, Costa V, Harding AM, Reznikov L, Benson CJ, Welsh MJ (2009) ASIC2 subunits target acid-sensing ion channels to the synapse via an association with PSD-95. J Neurosci 29:8438-8446.

Ziemann AE, Schnizler MK, Albert GW, Severson MA, Howard MA, 3rd, Welsh MJ, Wemmie JA (2008) Seizure termination by acidosis depends on ASIC1a. Nat Neurosci 11:816-822.

Ziemann AE, Allen JE, Dahdaleh NS, Drebot II, Coryell MW, Wunsch AM, Lynch CM, Faraci FM, Howard MA 3rd, Welsh MJ, Wemmie JA (2009) The amygdala is a chemosensor that detects carbon dioxide and acidosis to elicit fear behavior. Cell 139:1012-1021. 